\title{
Legal status and the criminal activity of immigrants
}

\author{
By Giovanni Mastrobuoni and Paolo Pinotti*
}

\begin{abstract}
We exploit exogenous variation in legal status following the January 2007 European Union enlargement to estimate its effect on immigrant crime. We difference out unobserved time-varying factors by i) comparing recidivism rates of immigrants from the "new" and "candidate" member countries; and ii) using arrest data on foreign detainees released upon a mass clemency that occurred in Italy in August 2006. The timing of the two events allows us to setup a difference-in-differences strategy. Legal status leads to a 50 percent reduction in recidivism, and explains one-half to two-thirds of the observed differences in crime rates between legal and illegal immigrants.
\end{abstract}

JEL: F22, K42, C41

Keywords: immigration, crime, legal status

In most developed countries the connection between immigration and crime is a heavily debated issue. Specifically, opinion surveys show that in North America and Europe citizens are deeply concerned about the perceived link between crime and immigrants, especially illegal ones (Mayda, 2006; Card, Dustmann and Preston, 2012). We argue that part of the debate might be driven by a vicious cycle between crime, citizens' perceptions, and migration restrictions.

Citizens may easily base their perceptions about the relationship between immigration and crime on the disproportionate presence of immigrants in Western prisons (see Figure 1]1. These figures increase the support for migration restrictions, preventing potential immigrants from legally residing in the destination country (Waters and Simes, 2013; Dinas

\footnotetext{
* Mastrobuoni: University of Essex, Collegio Carlo Alberto, IZA, and Netspar, Wivenhoe Park, CO34SQ Colchester, UK, gmastrob@essex.ac.uk. Pinotti: Bocconi University and BAFFI Center, Via Roentgen 1, 20136 Milan, Italy, paolo.pinotti@unibocconi.it. This is a heavily revised version of a previous paper circulated with the title Migration Restrictions and Criminal Behavior: Evidence From a Natural Experiment. We would like to thank Josh Angrist, Federico Cingano, David Card, Giacomo De Giorgi, Raquel Fernandez, Andrea Ichino, Justin McCrary, Enrico Moretti, Alfonso Rosolia, Adriaan Soetevent, Giordano Zevi, and seminar participants at the FEEM-CEPR Conference on Economics of Culture, Institutions and Crime, the Center for Studies in Economics and Finance in Naples, the University of Padua, the University of Paris X, the INSIDE Workshop in Barcelona, the NBER Summer Institute 2010 (Labor Studies and Crime groups), the Universitat van Amsterdam, Cornell University, Brown University, the Royal Economic Society Conference 2011 (special session on Immigration and Crime), and the LIEPPChicago Crime Conference for very useful comments. Financial support from the Collegio Carlo Alberto, the W.E. Upjohn Institute for Employment Research, and Fondazione Antonveneta is gratefully acknowledged. Giovanni Mastrobuoni thanks the staff at INSIDE at Universitat Autonoma de Barcelona University for their hospitality. Giancarlo Blangiardo kindly provided the ISMU data.

${ }^{i}$ Only recently has the US Department of Homeland Security released official data showing that immigrants appear to be over-represented in prisons and jails, not without critiques (Camarota and Vaughan, 2009). Before that, Stana (2005) had shown that foreigners are over-represented in federal prisons, while Butcher and Piehl (2007) had shown that according to the US Census, immigrants are under-represented among the population of "institutionalized" individuals, and that such population may serve as a proxy for the overall prison population.
} 
and van Spanje, 2011). However, stringent restrictions produce a pool of unauthorized immigrants, those who cross the border illegally or simply over-stay their tourist visas ${ }^{2}$ Migration restrictions are often coupled with work restrictions. Illegal immigrants are thus precluded from taking legal jobs and from receiving welfare benefits, which in turn would lower their opportunity cost of committing crimes. If this increases their criminal attitude and their likelihood of being imprisoned, the vicious cycle begins.

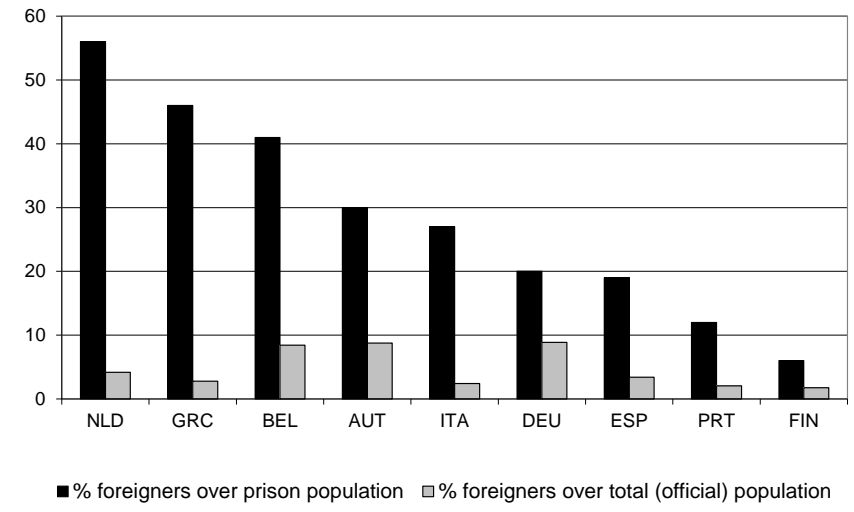

Figure 1. : Share of foreigners over prison population and total population in some OECD countries

Note: This figure shows the incidence of foreigners among the prison and total populations in some OECD countries in year 2000, or, when unavailable, in nearby years. Source: OECD

Whether there is such a cycle depends on the causal relationship between immigrants' legal status and crime. In principle the relationship can be quite complex, and before explaining how we plan to tackle this issue, it is useful break down the total effect into three parts. Granting legal status may (i) increase the inflow of new immigrants from abroad, (ii) prevent the deportation of those who are already present in the country, and (iii) reduce their propensity to engage in criminal activity, thanks to better outside opportunities in the legal sector. Since (i) and (ii) increase the pool of potential criminals, the sign of the overall effect is clearly ambiguous. Moreover, only (ii) and (iii) involve immigrants who are illegally residing in the country before legal status is granted.

This study will focus on estimating the effect on precisely these immigrants. The absence of official statistics on the illegal population, and the potential selection into legal status,

\footnotetext{
${ }^{2}$ In many developed countries the ratio between illegal and legal immigrants is estimated to be close to $1 / 3$ (see Fasani, 2008).
} 
constitute the main challenges to the identification of such an effect.

We address these two issues by exploiting, respectively, exogenous variation in legal status after the European Union (EU) enlargement of January 1, 2007 (the "treatment"), and unique data on the universe of prison inmates that were pardoned with the Collective Clemency Bill enacted in Italy five months before the enlargement, on August 1, 2006. As a consequence of the sudden, massive release of prison inmates, we can track contemporaneous recidivism of "treated" and "non-treated" immigrants during the periods before and after the enlargement (respectively, the light and dark areas in Figures 2 and 3 ).

The left panel of Figure 2 shows, on a six month frequency, the number of foreign prison inmates since 2012. The size of the foreign prison population decreased by 7,000 units, from about 20,000 to 13,000, between June 2006 and December 2006. This was largely a product of the pardon, which freed about 8,000 individuals in August 2007 and a few more over the following weeks (see the right panel of Figure 2). However, many of these individuals were soon rearrested-about 1,000 already by January 2007 (gray line).
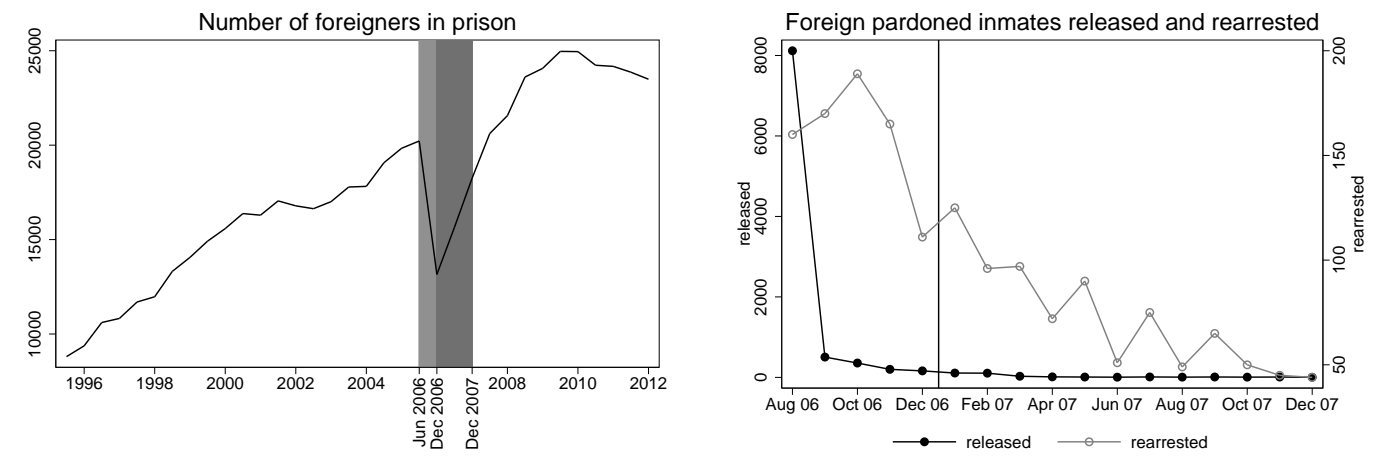

Figure 2. : Foreign prison population (left) and the number of inmates released and reincarcerated (right)

Note: The left figure plots the number of foreigners in prison since 1995, on a six month frequency. The right panel shows the number of foreign prison inmates released after the Collective Clemency Bill in August 2006 (left axis), as well as those re-incarcerated throughout December 2007 (right axis). The vertical line refers to the moment of the EU enlargement.

Source: Ministry of Justice.

We will focus on recidivism rates of inmates from certain countries, namely Romanians and Bulgarians, who acquired the right to reside and work in Italy (as in most other European countries) after the EU enlargement in January 2007. Figure 3 documents the treatment: The number of Romanians and Bulgarians tracked down by the Italian police (and often deported) drops from the tens of thousands to essentially zero, while no significant change is observed for illegal immigrants from countries that are expected to join the EU in the near future (Albania, Montenegro, Turkey, Bosnia and Herzegovina, Croatia, 
Iceland, Kosovo, and Serbia) $?^{3}$
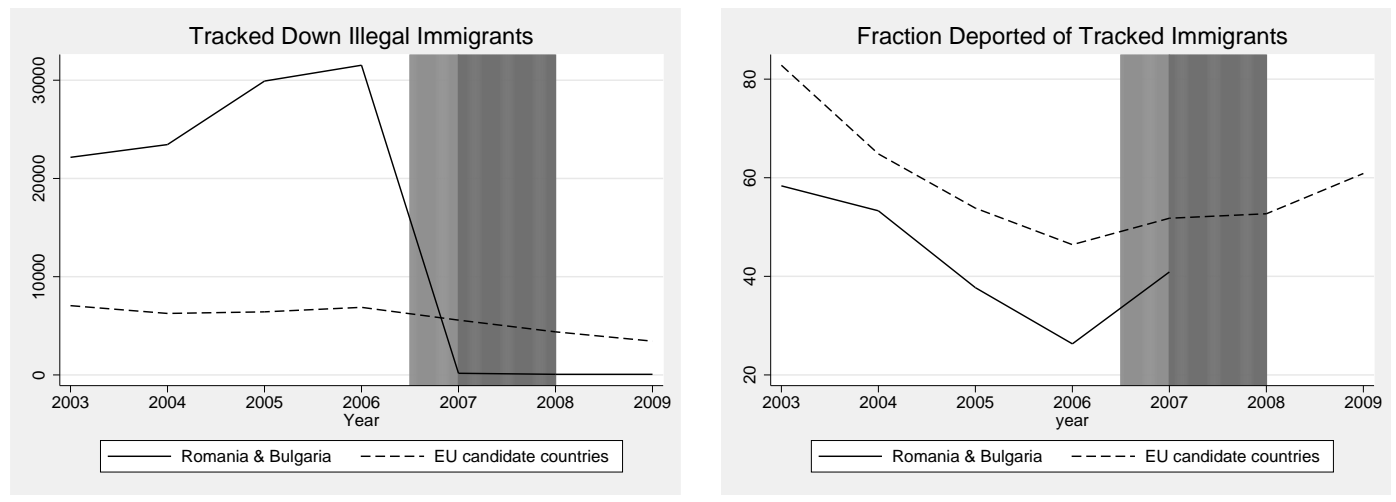

Figure 3. : Number of tracked-down immigrants, and the fraction expelled

Source: Marzio Barbagli and Asher Colombo (2010)

The unconditional difference-in-differences in recidivism rates of Romanians and Bulgarians relative to a control group of inmates from candidate EU member countries, before (August-December 2006) and after (January-June 2007) the enlargement, equals -3.2 percentage points, or -50 percent of the pretreatment recidivism (equal between the two groups). As in most other countries, illegal residence by itself is not a criminal offense, so it cannot explain these differences, nor can differential access to alternatives to institutionalization (e.g., home detention), because all recidivists have to face prison time. These results are confirmed when we control (using both semiparametric and parametric methods) for a baseline hazard function of time-at-risk, as well as for preenlargement differences between inmates from Romania and Bulgaria and inmates from the EU candidate countries.

It is difficult to judge the external validity of our estimate. On the one hand, former inmates are more likely to be at the margin between legal and illegal behavior, and so it is not surprising that recidivism studies form the bulk of the individual-level evidence in the empirical crime literature (see, for instance, Witte, 1980, Lee and McCrary, 2009). On the other hand, our quasi-experiment focuses on former inmates from a specific set of eastern European countries (mainly Romania, Bulgaria, and Albania). How representative is this group with respect to the total population of illegal immigrants in Italy (and, possibly, in Europe)? According to Eurostat data (Herm, 2008), in 2006 eastern Europeans represented 23 percent of all non-EU immigrants to Europe, and Romanians represented the largest non-EU group of immigrants to the EU.4 While we do not argue that our estimates apply generally to any immigrant group, the massive flows of eastern European

\footnotetext{
${ }^{3}$ The data in Figure 3 are only available for Romania, Bulgaria, Albania, Montenegro, and Turkey, yet the econometric analysis will be based on the entire population of released inmates.

${ }^{4}$ Such numbers increased after the enlargement. In 2012, Romanians alone represented 7 percent of all nonnationals living in the European Union, Albanians 3 percent, and Bulgarians 1.5 percent.
} 
immigrants (particularly Romanians) to several European countries extend the importance of our results beyond Italy.

The effects are also likely to differ depending on the value of legal status, which in turn depends on labor market conditions and the degree of illegality in the host country. In countries with slack labor markets or with large unofficial sectors, obtaining legal status may not be sufficient to improve immigrants' economic opportunities. In this respect, Italy, with its massive economic differences between a very poor South and a very rich North, is an ideal testing ground. Indeed, we find that recidivism falls only for economically motivated offenders, and the reductions are larger in areas offering better legitimate income opportunities to legal immigrants.

A battery of falsification tests suggest that these results are not driven by the specific characteristics of the control group, nor by other events occurring during the same period. Estimates of peer effects across nationalities refute that the estimates are biased by substitution or complementarity in crime between treated and control groups. Finally, we also discuss the possibility of differential attrition due to mobility across the border of the newly legalized immigrants, and we argue that mobility among Romanians and Bulgarians should have been greater before the acquisition of legal status - thus biasing our estimates toward zero.

To put our results in perspective, we show in the next section that legal immigrants in Italy have an 80-90 percent lower probability of being arrested compared to illegals. Therefore, our results suggest that the causal effect of legal status accounts for between $1 / 2$ and $2 / 3$ of this difference. The remaining part may be explained by selection into legal status, or a different probability of imprisonment conditional upon having committed a crime, or both. While these factors are kept constant across all pardoned inmates in our sample, legal and illegal immigrants would generally differ in these respects.

This paper contributes to the literature on the social and economic effects of immigration. Until very recently, research in this area has focused mainly on the labor market competition between immigrants and natives (surveys include Borjas, 1994; Friedberg and Hunt, 1995, Bauer, Lofstrom and Zimmermann, 2000, Card, 2005), as well as the effects of immigration on taxes (Storesletten, 2000 ; Lee and Miller, 2000; Chojnicki, Docquier and Ragot, 2005) and prices (Lach, 2007; Cortes, 2008). However, Card, Dustmann and Preston (2012) show that besides these more "economic" issues, natives' support for migration restrictions is also (and indeed mostly) shaped by other "compositional amenities", among which crime plays a major role (see also Bauer, Lofstrom and Zimmermann, 2000).

In response to these concerns, a burgeoning literature documents the empirical relationship between immigration and crime across local areas within the United States (Butcher and Piehl, 1998; Reid et al., 2005; Moehling and Piehl, 2009; Borjas, Grogger and Hanson, 2010, Wadsworth, 2010, Spenkuch, 2014), the United Kingdom (Bell, Machin and Fasani, 2013), Italy (Bianchi, Buonanno and Pinotti, 2010), and Spain (Alonso-Borrego, Garoupa and Vázquez, 2012). However, the effect of legal status on immigrants' crime has remained largely unexplored, despite there being ample evidence that legal status improves greatly the labor market opportunities of immigrants (Bratsberg, Ragan and Nasir, 2002; 
Kossoudji and Cobb-Clark, 2002, Kaushal, 2006, Amuedo-Dorantes, Bansak and Raphael, 2007; Lozano and Sorensen, 2011).

We fill this gap by estimating the causal effect of legal status on crime. In doing so, our paper complements parallel work on the consequences of the 1986 Immigration Reform and Control Act (IRCA), which granted legal status to unauthorized immigrants in the United States. Baker (2013) shows that the IRCA decreased local crime rates across U.S. counties, while Freedman, Owens and Bohn (2013) document an increase in the number of charges filed against Hispanic residents of San Antonio, Texas, after the expiration of the IRCA amnesty deadline. Relative to these papers, we take advantage of a clean quasiexperimental design and of longitudinal, individual-level data, which allow us to separate causal effects from selection.

Our results also speak to a large empirical literature on the relationship between legitimate income opportunities and criminal careers. The existence of such a relationship is indeed the key result of the economic model of crime (Becker, 1968), and several papers found a good deal of evidence consistent with it: a nonexhaustive list includes Witte (1980), Meyers (1983), Grogger (1998), Gould, Weinberg and Mustard (2002), and Machin and Meghir (2004). We show that even among foreign immigrants, access to better legitimate income opportunities - through the acquisition of legal status - lowers the propensity to engage in crime.

The paper is organized as follows. In the next section we describe the institutional features of the Italian migration system that are most relevant for our analysis; Section II] describes the natural experiment; Section III presents the empirical results; and Section IV concludes.

\section{Legal and illegal immigrants in Italy}

Immigration in Italy is a very recent phenomenon. After centuries of massive emigration, net inflows turned positive only in the late 1980s. During the past two decades, the number of foreign official residents rose from less than 600,000 to 4.5 million.

\section{A. Work permits}

The main way foreigners obtain legal residence in Italy is by receiving a work-related permit; however, the application procedure greatly hampers the match between demand and supply of foreign workers. In principle, migration law N. 189/2002 dictates that employers must post job offers in Italian consulates worldwide. Upon finding an employer who is willing to act as a sponsor, the prospective migrant is supposed to apply for a residence permit; if the application makes it into the yearly migration quotas set by the government, the prospective migrant receives a residence permit from the consulate and can finally migrate to Italy.

Given that it is almost impossible to find a sponsor without a direct contact, many immigrants cross the border illegally (or they enter the country as tourists and overstay the tourist visa) to search for an employer who is willing to sponsor their application. In 
practice, however, the chances of later regularization after entering illegally are extremely low, because of the tight rationing of residence permits. For instance, 170,000 permits were issued in 2007 against more than 740,000 applicants; the following year, the number of new residence permits decreased to 150,000 , to be assigned primarily to applications left pending the year before.

The systematic mismatch between applications and quotas creates a large pool of illegal immigrants, who have little or no chance of finding stable employment in the official sector and regularizing their residence status. Thus, most of them remain unemployed or work for lower wages in the unofficial economy, which in turn lowers the opportunity cost of engaging in outright criminal activities.

\section{B. Crime Rates}

An official report by the Italian Ministry of Interior shows that in 2006 (just before the EU enlargement) about 80 percent of all foreigners arrested by the police for having committed a crime in Italy were illegally present in the country (Italian Ministry of Internal Affairs, 2007, p. 360). However, to compute the crime rate of legal and illegal immigrants, one would need to know as well the size of the two groups (i.e., the denominator of the crime rate), which may be difficult to observe due to the very nature of illegal migration.

Still, amnesties of formerly undocumented immigrants provide useful information in this respect. On these occasions, illegal immigrants may, in fact, apply for a valid residence permit under very mild conditions, and thus have clear incentives to report their (illegal) status. General amnesties have been enacted every four to five years since 1986, growing in size from 100,000 to 250,000 individuals during the 1990s, and reaching a peak of 700,000 in 2002. These figures suggest that the growth of foreign residents in Italy was paralleled by that of unofficial immigrants, the latter representing about one-third of the total foreign population in 2002 (Figure 4 ) $5^{5}$

Combining these pieces of information, the relative crime rate of legal and illegal immigrants is

$$
\frac{E(C \mid L=1)}{E(C \mid L=0)} \approx 12.5 \%
$$

where $C=1$ for individuals reported by the police for having committed a crime and $C=0$ otherwise, and where $L=1$ and $L=0$ denote the groups of legal and illegal immigrants. This means that compared to legal immigrants, illegals are about eight times more likely to commit a crime ${ }^{6}$ Next, we examine what might explain such a stark difference in the

\footnotetext{
5 Bianchi, Buonanno and Pinotti (2010) and Fasani (2009) use applications for amnesty to estimate the size of the illegal population in Italy, Winegarden and Khor (1991) do the same for the United States after the IRCA.

${ }^{6}$ To compute 11 notice that

$$
\frac{E(C \mid L=1)}{E(C \mid L=0)}=\frac{c_{L}}{1-c_{L}} / \frac{r_{L}}{1-r_{L}}
$$

where $c_{L}$ and $r_{L}$ are the shares of legals among immigrants reported by the police and among all foreign residents,
} 


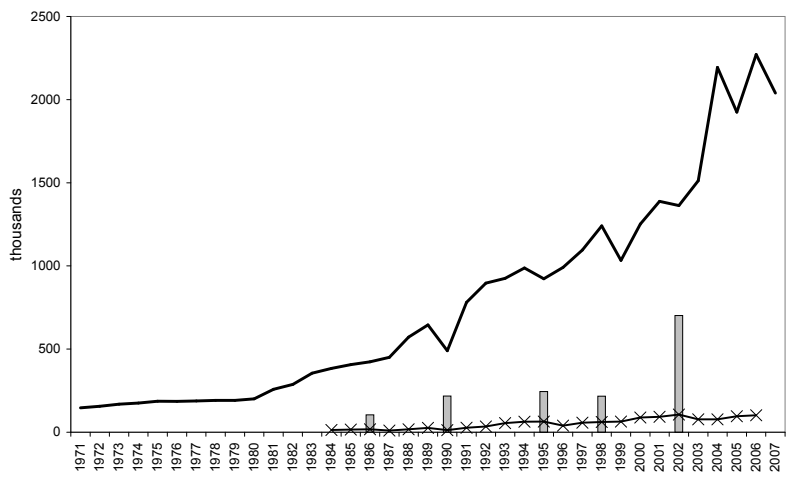

Figure 4. : Residence permits, amnesties of illegal immigrants, and deportations

Note: The figure shows the number of valid residence permits (since 1971), applications for regularization of formerly unofficial immigrants during the amnesty programs $(1986,1990,1995,1998,2002)$, and the number of deportations of undocumented immigrants over the period 1984-2006.

Source: Ministry of Interior.

likelihood of arrest.

\section{Deportations and Selection into Legal Status}

Much the same as in many Western countries, including the United States, residing illegally in Italy as an undocumented person is a civil offense, not a criminal offense (Waters and Simes, 2013).7 Illegal immigrants should be transferred to a detention center for unauthorized aliens and, unless they qualify as asylum seekers, they should be deported back to their country of origin. However, in many cases the procedure is not enforcedbecause of the overcrowding of the detention centers and the cost of deportations-in which case the apprehended immigrant simply receives an injunction to leave the country and is immediately released. Still, the fraction of immigrants who are deported is not negligible. Figure 4 shows that, for the years in which there was an amnesty, the ratio of expulsions over the total number of illegal immigrants (as measured by the number of applications

respectively, and let $c_{L} \approx 20 \%$ and $r_{L} \approx 67 \%$.

${ }^{7}$ In other words, illegal immigrants apprehended in Italy can not be sentenced to jail for the only reason of being illegally present on the territory. The last reform of Italian migration policy (Law N. 198/2002) introduced the possibility of incarceration for illegal immigrants that were reapprehended by the police after ignoring a previous injunction to leave the country. However, such a norm was never enforced and was later deemed anticonstitutional (sentence 223/2004 of the Constitutional Court, discussed in Ghersi 2005). Interestingly, in June 2012 the US Supreme Court rejected similar provisions contained in Arizona's immigration law. 
for amnesty) climbed from 17 percent in 1986 to 28 percent in 1998, eventually declining to 15 percent at the time of the last amnesty in 2002 .

Deportations reduce the number of crimes committed in Italy by expelling from the country a portion of the illegal immigrants, and some potential criminals among them. In particular, the ratio in Equation (1) can be decomposed as

$$
\frac{E(C \mid L=1)}{E(C \mid L=0)}=\frac{1}{1-E(D \mid L=0)} \times \frac{E(C \mid L=1)}{E(C \mid L=0, D=0)},
$$

where $D=1$ for the illegal immigrants who are deported and $D=0$ otherwise, so $E(D \mid L=$ $0)$ is the probability of deportation and $E(C \mid L=0, D=0)$ is the probability of committing a crime conditional upon not being deported. The first term on the right-hand side of Equation 22 reflects the incapacitation of illegal immigrants through deportations, as those who are deported cannot commit crimes in Italy.

Turning to the second term in Equation (2), it captures both the causal effect of legal status on the individual propensity to engage in crime, and selection bias. Framing the problem in the context of the potential outcome model (Rubin, 1974), it may be rewritten as

$$
\frac{E\left(C^{1} \mid L=1\right)}{E\left(C^{0} \mid L=0, D=0\right)}=\underbrace{\frac{E\left(C^{1} \mid L=1\right)}{E\left(C^{0} \mid L=1\right)}}_{\text {causal ef fect }} \times \underbrace{\frac{E\left(C^{0} \mid L=1\right)}{E\left(C^{0} \mid L=0, D=0\right)}}_{\text {selection }},
$$

where $C^{1}$ and $C^{0}$ are the potential outcomes conditional upon having or not having legal status, respectively. Selection bias is the main threat to identifying the causal effect, $E\left(C^{1} \mid L=1\right) / E\left(C^{0} \mid L=1\right)$, because we observe $C^{0}$ only when $L=0$, and, in general, legal and illegal immigrants have different individual characteristics. For instance, more educated individuals have better chances of finding employers willing to sponsor their work permits.

Such differences are indeed apparent from survey data collected in the northwest of Italy just before the EU enlargement. Since 2001, the Italian nongovernmental organization "Iniziative e Studi sulla Multietnicit" (ISMU) has conducted yearly interviews with a sample of about 9,000 immigrants in the region of Lombardy. Exploiting immigrants' networks around a number of "aggregation centers" (shops, telephone centers, bars, etc.), the sampling design allows for inclusion in the survey of the illegal component of the immigrant population (see Blangiardo (2008)). The results of the survey confirm that illegal immigrants are, on average, less educated than the legal ones; they also have lower earnings and lower skill-premiums (see Table 1), 8 There is also extensive evidence of the wage gap suffered by illegal immigrants in the United States (see, among others, Bratsberg, Ragan and Nasir, 2002, Kossoudji and Cobb-Clark, 2002; Kaushal, 2006; Lozano and Sorensen,

\footnotetext{
${ }^{8}$ Drawing upon several rounds of the ISMU survey, Accetturo and Infante $(2010)$ confirm these findings in a multivariate regression analysis.
} 
2011; Barcellos, 2011).

The observed differences in earnings may reflect both the direct effect of legal status, as illegals cannot work in the official economy, and selection into legal status, as witnessed by the significant differences in other (predetermined) individual characteristics. In particular, illegal immigrants are typically young, single males, and they are less educated and have fewer children than legal immigrants. All these characteristics are associated in general with a higher propensity to engage in crime, so the selection effect in Equation (2) may potentially explain a large part of the difference in criminal activity between legal and illegal immigrants. Our quasi-experimental design allows us to keep the composition of the two groups constant, in order to identify the causal effect of legal status.

Table 1-: Legal and illegal immigrants: Individual characteristics, and labor market outcomes.

\begin{tabular}{lcccccc}
\hline \hline Variable & \multicolumn{2}{c}{ Illegals } & & \multicolumn{2}{c}{ Legals } & Diff. \\
\cline { 2 - 3 } & obs & mean & & obs & mean & \\
\hline Age & 1280 & 31.29 & & 7343 & 34.63 & $-3.34^{* * *}$ \\
Female & & $(8.94)$ & & $(9.36)$ & $(0.28)$ \\
& 1281 & 0.39 & & 7353 & 0.44 & $-0.05^{* * *}$ \\
Married & & $(0.49)$ & & $(0.50)$ & $(0.01)$ \\
& 1281 & 0.34 & & 7353 & 0.59 & $-0.26^{* * *}$ \\
Number of kids & & $(0.47)$ & & $(0.49)$ & $(0.01)$ \\
College & 1279 & 0.76 & & 7339 & 1.18 & $-0.41^{* * *}$ \\
& & $(1.19)$ & & $(1.28)$ & $(0.04)$ \\
Low-skilled & 1281 & 0.14 & & 7353 & 0.16 & $-0.02^{* * *}$ \\
& & $(0.34)$ & & $(0.37)$ & $(0.01)$ \\
Income (euros per month) & 1281 & 0.12 & & 7353 & 0.09 & $0.04^{* *}$ \\
& & $(0.33)$ & & $(0.28)$ & $(0.01)$ \\
College premium & 949 & 824 & & 5339 & 1130 & $-306^{* * *}$ \\
& & $(371)$ & & $(652)$ & $(22)$ \\
& 949 & 9 & & 5339 & 112 & $-103^{*}$ \\
\hline \hline
\end{tabular}

Note: This table reports the average characteristics of legal and illegal immigrants, as well as the between-group difference in each variable. The source is the 2006 round of the ISMU survey, and the sample is representative of the entire immigrant population of the Italian region of Lombardy. Robust standard errors are reported in parentheses. ${ }^{*},{ }^{* *}$, and ${ }^{* * *}$ denote between-group differences that are statistically significant at the 90 percent confidence, 95 percent confidence and 99 percent confidence levels.

\section{The natural experiment}

\section{A. The EU enlargement}

In the wake of the EU enlargement, citizens of central and eastern European countries became a large and growing share of total immigration to Italy, reaching about half of the 
foreign (official) residents in 2011. The first round of the enlargement took place in 2004 with the admission of the Czech Republic, Estonia, Cyprus, Latvia, Lithuania, Hungary, Malta, Poland, Slovenia, and Slovakia. Then, on January 1, 2007, Bulgaria and Romania also joined the EU.

New EU member Countries. - Romanians and Bulgarians had already been given waivers to receive tourist visas to enter the EU with Council Regulation N. 539/2001, and the absence of migration barriers inside the single market area (after the Schengen Agreement of 1985) allowed them to move freely within the EU already before 2007. However, the waiver was limited to a maximum of 90 days in each EU member country, after which they had to move to another country, and they had no right to work there.

Compared to this former arrangement, Article 39 of the European Commission Treaty allows citizens of new member countries five advantages: It allows them to i) look for a job in any other country within the EU, ii) work there without needing any permit, iii) live there for that purpose, iv) stay until the end of the employment relationship, and v) enjoy equal treatment with natives in access to employment, working conditions, and all other social and tax advantages that may help integration inside the host country.

In practice, however, several countries in Europe maintained significant restrictions. In Italy as well, the application of the EU directives was at the center of a heated debate. On December 28, 2006 - just three days before the enlargement - the center-left government finally guaranteed full rights to the new EU citizens, lifting all restrictions on working in the following sectors: agriculture, hotel and tourism, managerial and highly skilled work, domestic work, care services, construction, engineering, and seasonal work. Such sectors, indeed, account for the bulk of immigrants' employment in Italy. In the rest of the official economy (basically the manufacturing sector) migration quotas were also eased in order to accommodate a larger number of workers from Romania and Bulgaria.

Therefore, admission to the EU basically removed the migration barriers faced by Romanians and Bulgarians in Italy, granting them full rights to reside and work (as opposed to a temporary residence permit, as was in place before 2007). For the purpose of estimating the effect of legal status, they will thus constitute the treated group.

EU CANDidATE MEMBER COUNTRIES. - The process of enlargement is far from over, as several countries are negotiating admission conditions with the EU; the EU candidate member countries are Albania, Bosnia and Herzegovina, Croatia, Iceland, Kosovo, Macedonia, Montenegro, Serbia, and Turkey 9

Such countries provide a natural control group for Romania and Bulgaria. They have already started negotiations with the EU to gain admittance, so they should be most comparable along the economic and political criteria required for admission. With the exception of Iceland, they all belong to the same geographical area (see Figure 5); with the further exception of Turkey, they also share a great deal of linguistic, cultural, and

\footnotetext{
${ }^{9}$ More details about the EU enlargement can be found at http://ec.europa.eu/enlargement/.
} 
historical heritage. In practice, our sample of prison inmates pardoned in Italy will include just a few individuals from Turkey (less than 1 percent of the total sample) and no one from Iceland.

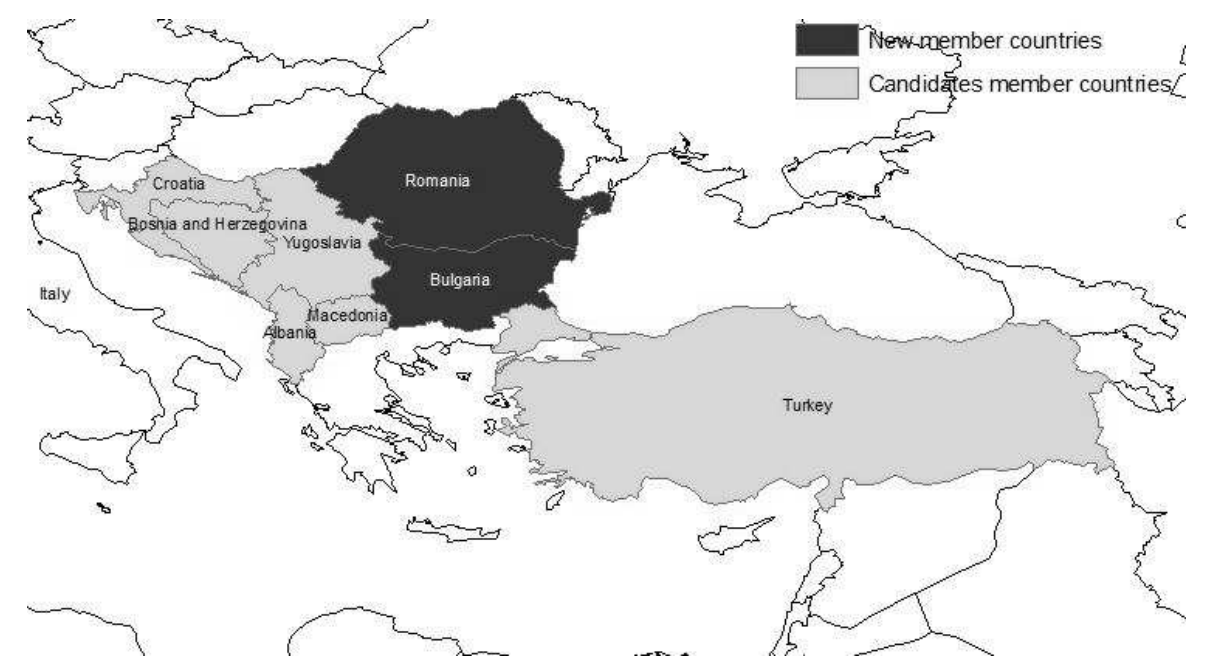

Figure 5. : New EU member and candidate member countries

Note: The map shows the countries admitted to the EU during the last round of the enlargement (in black), as well as the group of candidate member countries (in gray).

Source: European Commission.

The Effects of the EU Enlargement in Italy: Preliminary Evidence. - The left graph in Figure 6 shows the number of official residents for the treated and the control groups, before and after the enlargement. The difference remained constant until the end of 2006, the control group being about twice as large as the treated group. Then, in the wake of admission to the EU, the size of the treated group nearly doubled, while the control group continued to grow at approximately the same rate as in previous years.

The increase in the number of Romanians and Bulgarians arrested by the Italian police was much less pronounced, so the ratio of those arrested over total official residents actually declined for the treated group, while no significant change was observed for the control group (see the right graph of Figure 6). At first blush, one might be tempted to conclude that the removal of migration restrictions favored a decline in criminal activity. However, the increase in the number of Romanians and Bulgarians officially residing in the country includes both new immigrants and previous immigrants who acquired legal status only with the enlargement (but were also present before), the two groups being indistinguishable from each other. If the fraction of previously unofficial immigrants is nonnegligible, the statistics on official residents would underestimate the denominator of the crime rate before 

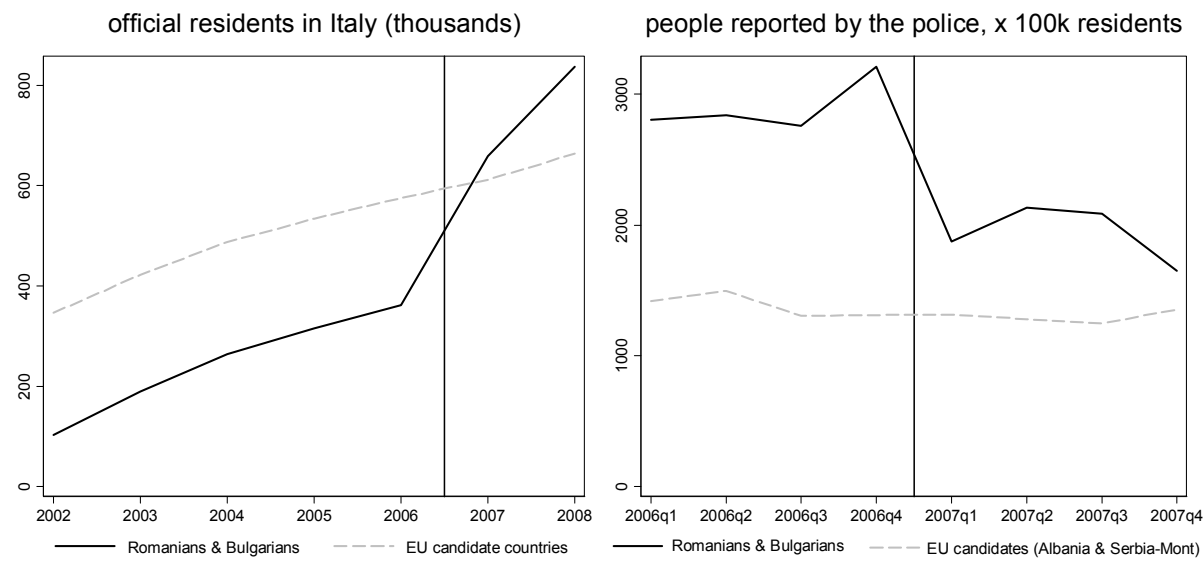

Figure 6. : Immigrants from new EU member and candidate member countries residing in Italy, and number of arrests

Note: The left graph plots the number of citizens of new EU member and candidate member countries officially residing in Italy during the period 2002-2008. The right graph shows, instead, the ratio of those by the police over the number of official residents arrested in each quarter during the period 2006-2007. In both graphs, the vertical line refers to the date of the last EU enlargement.

Source: ISTAT and Ministry of Interior.

the enlargement, so its decline after the enlargement would just be a statistical artifact of measurement error in the previous period. If the increase of official residents is instead driven by new inflows, the change in the crime rate would depend not only on the causal effect of legal status on previously unofficial immigrants, but also on the different selection of new immigrants after the enlargement.

One way to address these issues is to focus on a sample of immigrants who were already present in Italy before the enlargement.

\section{B. The July 2006 Collective Pardon}

Upon a collective pardon that was passed in July 2006, several hundred Romanian, Bulgarian, and other eastern European immigrants were released from prisons all over Italy. Collective clemency bills are deeply rooted in Italian history-over the last 40 years there has been on average one every five years (Barbarino and Mastrobuoni, 2014). Such pardons eliminate part of the inmates' sentences, typically two or three years, and inmates whose residual sentence is below such a length are immediately released. Given their wide reach, and a skewed distribution of residual jail time, pardons generate sudden releases of large numbers of inmates. The only offenders who do not receive pardons are mafia members, terrorists, kidnappers, and sexual offenders, but even violent offenders, like murderers and robbers, are released. 
The last pardon was voted on by the Italian Parliament in July 2006 and enacted shortly thereafter (on August 1). We were granted access to the criminal records of all prison inmates released on this occasion, including the exact dates of release and reincarceration (if any) up until December 2007, their nationality, and a few other individual characteristics.

About 22,000 individuals, corresponding to more than one-third of the total prison population, were freed over a few days. More than 8,000 of them were foreigners, and with subsequent releases their number grew to total 9,642 by the end of 2006 . Since a necessary condition for obtaining a residence permit in Italy is having a clean criminal record and a job, these individuals were illegal at the time of the pardon and should have been immediately deported upon release. However, because of the massive size of the release, only a handful of released inmates ( 7 in total, believed to be Islamic fundamentalists from Algeria and Morocco) were expelled from the country (Italian Ministry of Internal Affairs, 2007). This explains why so many released inmates were able to recidivate and were back in jail within a few days or weeks. About 800 were back by the end of 2006, before the EU enlargement, and their number grew to 1,654 one year later, after the EU enlargement (Figure 2). Our empirical strategy consists of comparing the recidivism of pardoned inmates in the treated and control groups, before and after the EU enlargement.

When interpreting the results, we take advantage of two other important aspects of our quasi-experimental design. First, immigrants with a criminal record cannot apply for a residence permit, so the only ones among pardoned inmates who acquired legal status because of the European enlargement between 2006 and 2007 were those in the treated group 10 While immigration amnesties would hardly be granted to ex-convicts, the EU legislation grants legal status universally: ${ }^{11}$

Second, prison inmates pardoned with the Clemency Bill would be sent to jail immediately upon recidivating, regardless of their legal status. This prevents the emergence of the following bias. While immigrants are not incarcerated only for being illegally present in Italian territory (see Section I.C), they may still experience a higher probability of incarceration conditional upon having committed a crime. According to law, suspect offenders can be incarcerated before trial if caught "red-handed" (flagranza di reato), or whenever there is a significant risk that they will either destroy the evidence, recommit the same crime, or escape judgment (upon decision of a special court, Giudice per le indagini preliminari). Since illegal immigrants are usually deemed at greater risk of bad conduct they may, in general, be more likely to be incarcerated than legal immigrants.

This is not true, however, in our sample of pardoned prison inmates, as previous offenders are always deemed at high risk and incarcerated immediately upon arrest (regardless of legal status). Moreover, the pardoned individual rearrested within 5 years of the release must go back to jail to serve the residual sentence that was pardoned, with no possibility of benefiting from alternative forms of detention (e.g. home detention). This means that the police forces would have the same incentives to target pardoned Romanians and Bulgarians

\footnotetext{
${ }^{10}$ In any case, noncompliance with treatment - i.e., the presence of some individuals in the control group obtaining legal status - would bias our estimates toward zero.

${ }^{11}$ It is considerably more cumbersome to expel EU nonnationals.
} 
and pardoned criminals from EU candidate countries. There is no obvious reason why it should be easier to arrest and build the case against one group over the other, and why, assuming there is such a difference, the difference would have to change with legal status. Finally, no bail is allowed in the Italian judicial system.

These features of the Clemency Bill - and, more generally, of the Italian judicial system - thus allow an interpretation of the relative changes in incarceration rates between the treated and control groups as changes in the underlying criminal activity.

\section{Sample}

Our sample includes about 800 Romanians and Bulgarians, as well as 1,800 immigrants from candidate member countries (none from Iceland). To reduce heterogeneity we restrict the analysis to males - about 90 percent of the total sample - so we are left with 725 and 1,622 individuals in the treated and control groups, respectively. The row headings down the left margin columns of Table 2 categorize the two groups in terms of the observable characteristics reported in our data: age, gender, marital status, education (missing for many observations), the type of crime for which the individual was first incarcerated before the pardon (possibly more than one, so the group means of economic and violent crimes do not add up to one), the length of the original sentence, and the months commuted under the pardon 12

While marital status is not significantly different, Romanians and Bulgarians are on average younger and more educated than individuals in the control group; they are also more (less) likely to commit violent (economic) crimes, but receive on average lighter sentences. One reason may be that the migration waves from some countries in the control group (notably Albania and the former Yugoslavia) predate those from Romania and Bulgaria, which makes for longer criminal careers in Italy, a higher incidence of repeat offenders, and longer sentences as a consequence. To the extent that such differences are correlated with criminal activity, the "parallel paths" assumption behind our difference-in-differences approach may be violated.

However, if we are willing to assume that deviations from the "parallel paths" depend solely upon differences in observable characteristics, conditioning on such differences removes all biases. While conditional independence may be a stringent requirement, notice that we are imposing it on changes in the crime rate over time (as opposed to levels); that is, we allow for (time-invariant) differences between groups to persist even after conditioning on observable characteristics. Most importantly, the availability of longitudinal data for the pretreatment period provides us with the opportunity to investigate the plausibility of this assumption.

Following Abadie (2005), we thus weight observations by the (inverse) propensity score of assignment-i.e., the probability of belonging to each group, conditional upon the observed

\footnotetext{
${ }^{12}$ The data also report the prison from which the individual was released (167 institutes in total), which we use later in the analysis.
} 
covariates. Specifically, the weight attached to each $i$-th observation is

$$
\text { new } E U_{i} \frac{p}{P\left(X_{i}\right)}+\left(1-n e w E U_{i}\right) \frac{1-p}{1-P\left(X_{i}\right)},
$$

where new $E U_{i}$ is a dummy equal to 1 if the individual is a citizen of new EU member countries and 0 otherwise, $p$ is the unconditional probability of belonging to the new EU group, and $P\left(X_{i}\right)$ is the probability conditional on the vector of individual characteristics $X_{i}$. The weighting scheme enhances comparability between the two groups by attaching more weight to units that are more similar to the other group relative to the average individual in the sample ${ }^{13}$

To estimate the propensity score we estimate a logit regression for the probability of being Romanian or Bulgarian, conditional upon the following vector of covariates: a quadratic polynomial in age, marital status, education (indicator variables for illiteracy, primary school, and secondary school, as well as for missing information on education), type of crime committed when first incarcerated (seven categories), a quadratic polynomial in sentence and commuted sentence, and a full set of fixed effects for the region where the prison from which the individual was released is located ${ }^{14}$ As expected, there is a tail of individuals in the control group whose estimated propensity score is close to zero, meaning they are very different (in terms of observable characteristics) from Romanians and Bulgarians (see Figure 7). The inverse propensity score-weighting reduces the importance of such observations, while it increases the weight of observations in both groups that lie in the middle of the distribution of the estimated propensity score.

The right columns of Table 2 show that weighting observations according to Equation (4) indeed eliminates all differences in average group characteristics. Whether it also eliminates differences in unobservable characteristics is basically untestable, yet differences in preenlargement outcomes between the treated and control groups, which we examine next, allow us to assess the credibility of the conditional independence assumption.

\section{Results}

This section presents our estimates of the effect of changes in legal status on the number of crimes committed by immigrants. We start by nonparametrically comparing differences in the hazard rate of reincarceration (i.e., the probability of being reincarcerated in a given period conditional upon not having been reincarcerated before) between the treated and control groups, before and after the enlargement, then we estimate semiparametric and fully parametric maximum likelihood hazard rate models. We conclude with a series of robustness exercises and falsification tests.

\footnotetext{
${ }^{13}$ One important advantage of propensity score weighting, relative to other matching estimators, is the possibility of computing asymptotically valid standard errors by bootstrapping methods (Abadie and Imbens, 2008).

${ }^{14}$ We dropped a few observations for which some covariates other than schooling were missing.
} 


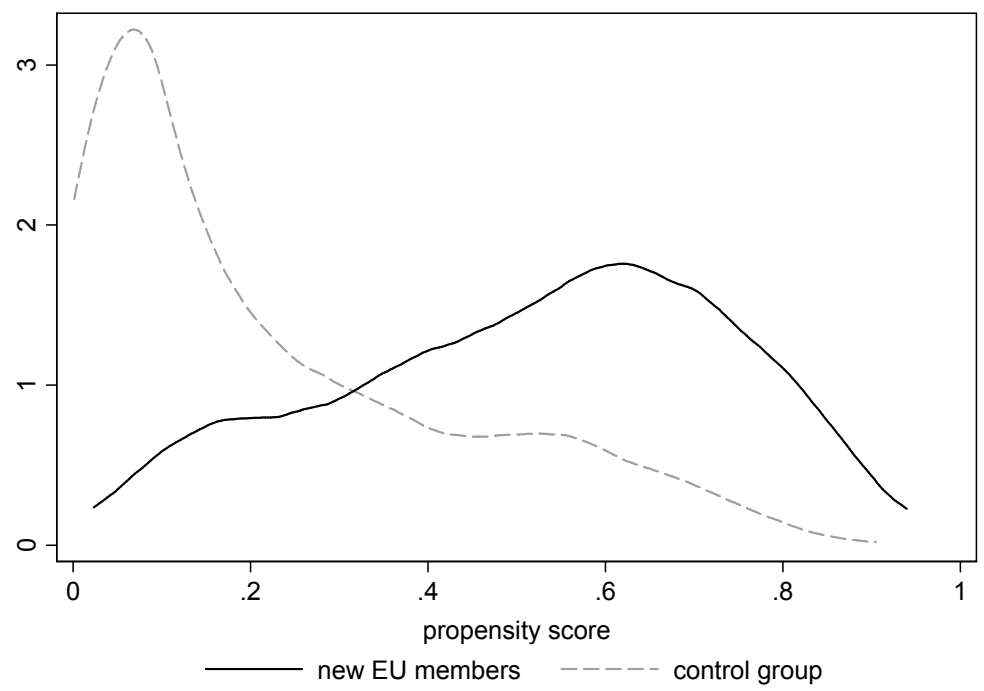

Figure 7. : Propensity score weighting

Note: The figure shows the kernel density of the estimated propensity score across groups. The propensity score is the probability of belonging to the groups of citizens of new EU member countries, conditional upon observable characteristics. The estimate is based on a logit regression of a dummy for being Romanian and Bulgarian on a flexible specification of the individual information included in our sample.

\section{A. Preliminary Evidence}

Figure 8 shows nonparametric estimates of the daily (log) hazard rates of reincarceration for pardoned individuals from new EU member and candidate member countries. For the sake of graphical illustration, we focus on inmates released during the first week after the pardon (1,392 individuals out of 2,347 in our sample), so the horizontal axis represents (approximately) the same duration-at-risk for all individuals 15 Since we are particularly interested in the effect of legal status through legitimate earning opportunities, we focus on individuals who were first arrested (before the pardon) for economically motivated crimes (mainly property and drug-related offenses) 16

The left panel shows the results obtained using the raw data-i.e., before applying the weighting scheme. While Romanians and Bulgarians display greater recidivism during the first months after the pardon, the opposite is true after they obtain legal status. As to the plausibility of the main identifying assumption, the evidence from the preenlargement period seems broadly consistent with the hypothesis of parallel outcomes (absent the policy change). After weighting observations by the inverse propensity score (right panel), the

\footnotetext{
${ }^{15}$ All estimates presented next are based on the total sample.

${ }^{16}$ The data do not contain information on the crimes committed after the pardon.
} 
Table 2-: Sample statistics by group, raw and propensity score-weighted data.

\begin{tabular}{|c|c|c|c|c|c|c|c|c|}
\hline & \multicolumn{5}{|c|}{ Nonweighted Sample } & \multicolumn{3}{|c|}{ Propensity score-weighted } \\
\hline & \multicolumn{2}{|c|}{ New EU } & \multicolumn{2}{|c|}{ Control } & \multirow[t]{2}{*}{ Diff } & \multirow{2}{*}{$\begin{array}{c}\text { New EU } \\
\text { mean }\end{array}$} & \multirow{2}{*}{$\begin{array}{c}\text { Control } \\
\text { mean }\end{array}$} & \multirow[t]{2}{*}{ Diff } \\
\hline & $o b s$ & mean & obs & mean & & & & \\
\hline Age & 725 & $\begin{array}{c}31.083 \\
(7.597)\end{array}$ & 1622 & $\begin{array}{c}33.269 \\
(8.088)\end{array}$ & $\begin{array}{c}-2.187^{* * *} \\
(0.355)\end{array}$ & $\begin{array}{c}33.335 \\
(8.528)\end{array}$ & $\begin{array}{c}32.716 \\
(7.914)\end{array}$ & $\begin{array}{l}0.619 \\
(0.38)\end{array}$ \\
\hline Low education & 725 & $\begin{array}{l}0.339 \\
(0.474)\end{array}$ & 1622 & $\begin{array}{c}0.461 \\
(0.499)\end{array}$ & $\begin{array}{c}-0.122^{* * *} \\
(0.022)\end{array}$ & $\begin{array}{l}0.437 \\
(0.496)\end{array}$ & $\begin{array}{c}0.422 \\
(0.494)\end{array}$ & $\begin{array}{l}0.015 \\
(0.023)\end{array}$ \\
\hline No education & 725 & $\begin{array}{c}0.017 \\
(0.128)\end{array}$ & 1622 & $\begin{array}{c}0.017 \\
(0.128)\end{array}$ & $\begin{array}{c}-0.0001 \\
(0.006)\end{array}$ & $\begin{array}{c}0.015 \\
(0.122)\end{array}$ & $\begin{array}{c}0.018 \\
(0.133)\end{array}$ & $\begin{array}{r}-0.003 \\
(0.006)\end{array}$ \\
\hline Education missing & 725 & $\begin{array}{c}0.539 \\
(0.499)\end{array}$ & 1622 & $\begin{array}{c}0.404 \\
(0.491)\end{array}$ & $\begin{array}{c}0.135^{* * *} \\
(0.022)\end{array}$ & $\begin{array}{c}0.437 \\
(0.496)\end{array}$ & $\begin{array}{l}0.450 \\
(0.498)\end{array}$ & $\begin{array}{r}-0.013 \\
(0.024)\end{array}$ \\
\hline Married & 725 & $\begin{array}{c}0.257 \\
(0.437)\end{array}$ & 1622 & $\begin{array}{l}0.288 \\
(0.453)\end{array}$ & $\begin{array}{c}-0.031 \\
(0.02)\end{array}$ & $\begin{array}{c}0.266 \\
(0.442)\end{array}$ & $\begin{array}{c}0.277 \\
(0.448)\end{array}$ & $\begin{array}{r}-0.011 \\
(0.021)\end{array}$ \\
\hline Economic crimes & 725 & $\begin{array}{c}0.84 \\
(0.367)\end{array}$ & 1622 & $\begin{array}{c}0.894 \\
(0.308)\end{array}$ & $\begin{array}{c}-0.054^{* * *} \\
(0.015)\end{array}$ & $\begin{array}{l}0.857 \\
(0.35)\end{array}$ & $\begin{array}{c}0.877 \\
(0.328)\end{array}$ & $\begin{array}{c}-0.02 \\
(0.016)\end{array}$ \\
\hline Violent crimes & 725 & $\begin{array}{c}0.295 \\
(0.456)\end{array}$ & 1622 & $\begin{array}{c}0.242 \\
(0.428)\end{array}$ & $\begin{array}{c}0.053^{* * *} \\
(0.02)\end{array}$ & $\begin{array}{l}0.284 \\
(0.451)\end{array}$ & $\begin{array}{l}0.262 \\
(0.44)\end{array}$ & $\begin{array}{l}0.022 \\
(0.021)\end{array}$ \\
\hline Sentence (months) & 725 & $\begin{array}{c}20.31 \\
(20.706)\end{array}$ & 1622 & $\begin{array}{c}39.183 \\
(32.33)\end{array}$ & $\begin{array}{c}-18.873^{* * *} \\
\quad(1.306)\end{array}$ & $\begin{array}{c}32.115 \\
(30.63)\end{array}$ & $\begin{array}{c}33.269 \\
(30.593)\end{array}$ & $\begin{array}{l}-1.154 \\
(1.435)\end{array}$ \\
\hline Residual sentence & 725 & $\begin{array}{c}9.305 \\
(10.615)\end{array}$ & 1622 & $\begin{array}{c}15.727 \\
(14.784)\end{array}$ & $\begin{array}{c}-6.423^{* * *} \\
(0.609)\end{array}$ & $\begin{array}{c}13.349 \\
(12.917)\end{array}$ & $\begin{array}{c}13.83 \\
(14.13)\end{array}$ & $\begin{array}{r}-0.481 \\
(0.646)\end{array}$ \\
\hline
\end{tabular}

$\overline{\text { Note: This table compares the characteristics of Romanians and Bulgarians in our sample with the group of citizens }}$ from EU candidate member countries. The first three columns report non-weighted averages for each group, as well as the between-group difference for each variable. In the last three columns, observations are weighted by the inverse propensity score, according to Equation (4). Robust standard errors are reported in parentheses. *, **, and *** denote between-group differences that are statistically significant at the 90 percent confidence, 95 percent confidence, and 99 percent confidence levels.

level of the hazard rate is also very similar between the two groups, which provides strong support for conditional independence.

To quantify the effect of legal status, in Table 3 we tabulate the hazard rate of rearrest for each group over the last two trimesters of 2006 and the first two of 2007, their differences, and the difference-in-differences; we report both robust and bootstrapped standard errors clustered by nationality and region. ${ }^{17}$ This allows for criminal activity to be correlated across inmates of the same nationality who (likely) reside in the same region. While bootstrapping generally leads to valid standard errors and confidence intervals for propensity score-weighting estimators (Abadie and Imbens, 2008), Busso, DiNardo and McCrary (2009) show that, for a sufficiently large number of observations, heteroskedasticity-robust standard errors provide a good approximation. The two estimates of the standard errors in Table 3 are actually extremely similar; thus, for the sake of computational efficiency, inference on the maximum likelihood models will be based on robust (clustered) standard

\footnotetext{
${ }^{17}$ Italy is divided into 20 regions and there are eight different nationalities in our sample. Since not all nationalities are represented in all regions, the number of clusters is equal to 129.
} 

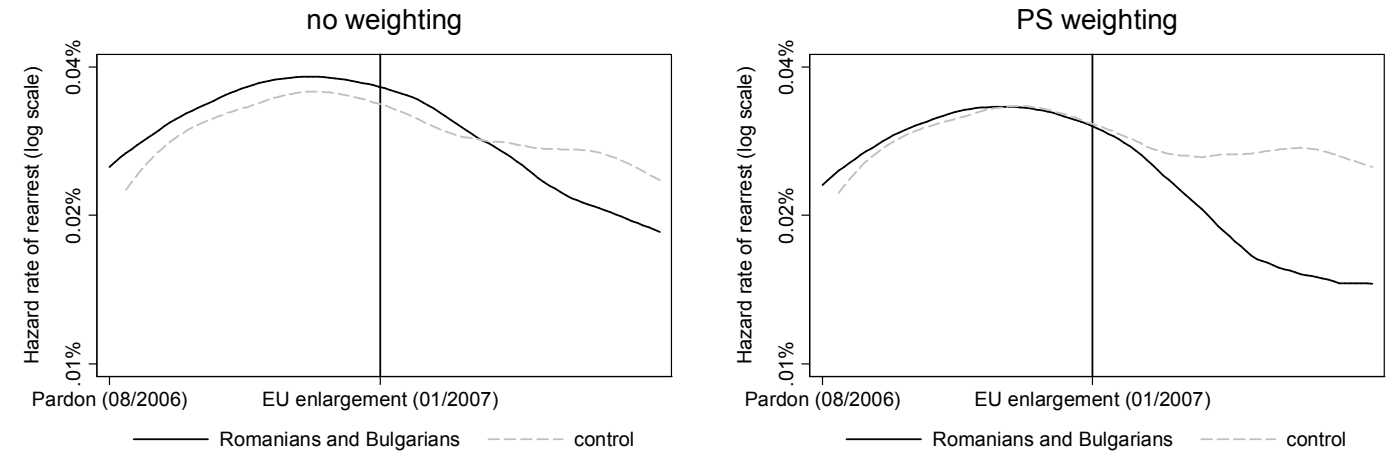

Figure 8. : Hazard rates of rearrest for pardoned inmates from new EU member and candidate member countries

Note: The figure plots the nonparametric (Nelson-Aalen) estimates of daily log hazard rates of re-incarceration between between August 2006 and May 2007 for Romanians and Bulgarians (solid line) and for the control group (dashed line). The scale on the vertical axis reports the (estimated) hazard rate of re-incarceration in each day. The left graph does not use weights, while in the right graph observations are weighted by the (estimated) propensity score according to Equation (4).

errors.

The top left panel of the table shows the results for economically motivated offenders. The second row confirms that, after weighting by the propensity score, the probability of incarceration in the pretreatment period is identical between the two groups. The hazard rate of Romanians and Bulgarians decreases from 5.8 percent to 2.3 percent after the policy change, while it is unaffected for the control group; as a result, the difference-indifferences is negative (-3.2 percent) and statistically significant at conventional confidence levels. These numbers imply that the hazard ratio of committing a crime between legal and illegal immigrants is close to 43 percent $(0.023 / 0.054)$. In light of the simple framework in Section I, the reduction in the propensity to commit crimes for immigrants in the treated group (the second term on the right-hand side of Equation 2) outweighs the fact that the potential criminals among them are not expelled any longer (the first term on the right hand side of the equation).

The opposite is true for violent offenders (top right panel), though the result is not statistically significant 18 For such offenders, criminal activity should depend to a lesser extent on economic motives (Machin and Meghir, 2004), so changes in labor market opportunities play only a minor role, and the effect of the negative change in deportations prevails.

Heterogeneity in the effect across criminal types is consistent with the fact that legal

\footnotetext{
${ }^{18}$ To be as conservative as possible, we include in this category individuals who were previously in prison for having committed only violent crimes; those reported for both economic and violent crimes are included among economically motivated offenders, as the latter crimes could be tied to the former ones (e.g. an assault during a robbery).
} 
status may affect criminal behavior by changing the labor market opportunities of the legalized immigrants. While we cannot provide hard evidence in this respect, as we do not observe the labor market outcomes of immigrants in our sample, additional heterogeneity in the effect across Italian regions is also consistent with such a mechanism. It is a well known fact that northern Italy is economically much more developed than the south, with GDP per capita differences that are close to 50 percent ${ }^{19}$ One aspect of this economic divide is that the relative size of the unofficial economy is twice as large in the south as in the north, so the change in labor market opportunities associated with the acquisition of legal status should be greater in the latter than in the former. If legal status reduces crime because it improves economic prospects in the official sector, one would then expect the reduction to be concentrated in the north. This is exactly the picture that emerges from Table 3 (bottom panels). The change in the fraction of Romanians and Bulgarians reincarcerated for economic crimes in the north between 2006 and 2007, as well as the difference-in-differences relative to the control group, is almost twice as large as the change based on the whole country, while no significant differences show up in the south.

\section{B. Cox Model}

To probe these results further, and to exploit all the information about the dates of release and rearrest, we fit a maximum-likelihood model for the hazard rate of reincarceration. Following most empirical applications of survival analysis (see Van den Berg, 2001, for a survey), we restrict ourselves to the class of proportional hazard models, in which the hazard rate is the product of a common function of time-at-risk and an exponential function of observable covariates. Specifically, the estimating equation is

$$
h(J \mid t, x)=\lambda(t) \exp \left(\alpha_{0} \text { post }+\alpha_{1} \text { new } E U+\beta \text { post } \times \text { new } E U+z^{\prime} \gamma\right)
$$

where $h(J \mid t, x)$ is the hazard rate of reincarceration after $t$ days since release from prison, conditional on a vector $x$, including a dummy post for the (calendar) period after the enlargement, a dummy new $E U$ for individuals in the treated group, the interaction between the two, and a vector of other observable characteristics $z$; finally, $\lambda(t)$ is a common function of the time-at-risk. Following the semi-parametric approach devised by Cox $(1972)$, we leave the baseline hazard function $\lambda(t)$ totally unrestricted and estimate the other coefficients by partial maximum likelihood. This way we take advantage of the tractability of the proportional hazard model, while allowing at the same time for significant flexibility in terms of functional form. Standard errors are clustered by Italian region and country of origin to allow for within-network correlation in criminal activity 20

The estimated coefficient $\beta$ captures the difference-in-differences between the hazard rate

\footnotetext{
${ }^{19}$ The economic divide between northern and southern Italy has long been studied (see, for instance, Eckaus 1961 Helliwell and Putnam 1995). Estimates of GDP differences are provided by the Italian Statistical Office, http://www.istat.it/it/archivio/52316

${ }^{20} \mathrm{In}$ Section III.C we show that the results change little when we generalize the proportional hazard model to allow for unobserved heterogeneity and when we go for a fully parametric approach.
} 
of reincarceration for the treated and control groups, before and after the EU enlargement, controlling for group-specific effects, calendar time periods, time-at-risk, and other individual characteristics. The exponentiated coefficient of the interaction term, $\exp (\beta)$, provides an estimate for the hazard ratio of legal status-i.e., the (constant) percentage effect of legal status on the probability of reincarceration. Such probability equals the probability of going to jail, conditional upon having committed a crime, times the hazard ratio of committing a crime,

$$
\frac{h(J \mid L=1)}{h(J \mid L=0)}=\frac{\operatorname{Prob}(J \mid C, L=1)}{\operatorname{Prob}(J \mid C, L=0)} \frac{h(C \mid L=1)}{h(C \mid L=0)} .
$$

As long as the probability of incarceration conditional upon having committed a crime is constant across the individuals in our sample (see the discussion in Section II.B), the first term on the right-hand side equals 1 , so the exponentiated coefficient (6) provides an estimate of the causal effect of legal status on the probability of committing a crime in Equation (3).

The results are presented in Table 4. The coefficient of the interaction term is negative, statistically significant (at the 95 percent confidence level), and very high in absolute value. The exponentiated coefficient suggests that the hazard ratio of legal status is about 57 percent. These findings are unaffected when we control for the individual characteristics reported in our data (column 2), which is consistent with the fact that the propensity score weighting guarantees the comparability of the two groups in terms of observable characteristics. (Notice also that the estimate for the group indicator is always very close to 0 .

Columns (3) and (4) distinguish between different types of offenders. In line with the means comparisons in Table 3, the overall effect is driven by a reduction in the criminal activity of individuals who were previously incarcerated for economic crimes, while the hazard rate of reincarceration increases slightly for violent offenders (although this latter effect is very imprecisely estimated). Finally, columns (5) and (6) confirm that the reduction in the hazard rate for economically motivated offenders is much stronger in northern regions.

The results in Tables 3 and 4 uncover a strong negative effect of legal status on the hazard rate of committing a crime in Italy. According to such results, the hazard ratio of legal status is slightly above 50 percent for economic crimes, and is less than 40 percent in northern regions. This is a sizable effect. In Section I.B we showed that, based on the available estimates of the unofficial foreign population in Italy, the incarceration rate for legal immigrants is about 12.5 percent that of illegal immigrants (see Equation 1). The causal effect of legal status would then account for $1 / 2$ to $2 / 3$ of such a difference. The remaining part would likely be explained by (positive) selection into legal status, as well as by differences in the probability of incarceration conditional upon having committed a crime. The latter is constant across our sample of former prison inmates, but could vary in general between legal and illegal immigrants in Italy (see the discussion at the end of Section II.B. 
As for violent offenders, the maximum likelihood estimates are also qualitatively similar to the results in Table 3 , the hazard rate of reincarceration increases, although the effect is small and not statistically significant. Interestingly, if we plug a deportation rate of about 15 percent (see Section I.C) into Equation (2), and we compute the hazard ratio conditional on not being deported (i.e., the second term on the right-hand side of the equation), such a number would be very close to unity, $1.27 *(1-0.15) \approx 1.07$. This is indeed consistent with the idea that legal status should have little or no effect on the behavior of violent criminals, and the only reason why the crime rate increases for this group is that they are not deported any longer after the acquisition of legal status.

\section{Robustness}

Next we subject our results to several robustness exercises and falsification tests.

FunCtional FORM AND UNOBSERVED HETEROGENEITY. - One issue concerns the functional form and the estimation method. The flexibility allowed for by semi-parametric estimation of the Cox model comes at a cost in terms of statistical power. For this reason, we estimate a fully parametric model that imposes a logistic form on the probability of re-incarceration. To condition the probability of rearrest on not having been rearrested before, we follow Efron (1988) and estimate the model on the weekly (unbalanced) panel of inmates who are at risk of incarceration during each period ${ }^{21}$ The results, presented in Table 5 , are in line with those obtained for the semi-parametric model, both in terms of statistical significance and magnitude. ${ }^{22}$

Another concern is unobserved heterogeneity. A fairly general result in the econometrics of survival analysis is that variation in omitted factors would bias the estimates of both the baseline hazard and the regressors' coefficients, no matter what the correlation between the included and excluded variables may be (see the discussion in Van den Berg, 2001) 23 Notice that our difference-in-differences specification allows for the presence of common unobserved heterogeneity in both the treated and control groups. The only serious threat to identification would be the presence of a different degree of heterogeneity within the two groups (i.e., a different distribution of $u$ ), but this seems unlikely given that such groups are similar in terms of observable characteristics and preenlargement outcomes (see Figure 8 and Table 3.

\footnotetext{
${ }^{21}$ In practice, the cross section of observations for the first week includes all individuals released immediately after the pardon, the one for the second week includes all those released until then and not re-incarcerated in the first week, and so on; in this way we end up with approximately 142,000 person-week observations. Lee and McCrary (2009) also adopt this strategy to estimate an empirical model of recidivism, while Ashenfelter and Card (2002) apply the same methodology to study retirement choices.

${ }^{22}$ As shown in Allison (1982) and Card and Levine (2000), the two models give similar results as long as the hazard rates are low.

${ }^{23}$ The intuition is easier to see for the baseline hazard: Whenever there is omitted heterogeneity in the hazard rates, having individuals with the highest (lowest) hazards leaving the pool of those at risk earlier (later) would be observationally equivalent to negative duration dependence. A similar argument applies to the derivative of the (log) hazard rate with respect to the vector of covariates.
} 
In any event, we augment the proportional hazard model in (6) with an unobserved component $u$, distributed according to the density $g(u)$. Mixed proportional hazard models of this sort can be estimated parametrically assuming that $g($.$) is a Gamma distribution$ and $\lambda(t)$ is a parametric function of time-at-risk $t$. We estimated both a Weibull and an exponential model, and we could not reject the latter (i.e., $\lambda$ is simply a constant). Table 6 compares the estimates of the exponential model with and without unobserved heterogeneity. No matter which specification and sample are chosen, without controlling for unobserved heterogeneity, the estimated coefficients of the exponential model are very similar to those of the Cox model. More importantly, allowing for unobserved heterogeneity increases the magnitude of the interaction coefficient, suggesting an even lower hazard ratio of legal status (about 40 percent for economic offenders, down to 27 percent in northern regions).

Placebo Regressions. - Another concern is that the results might depend on the choice of the control group. While candidate EU member countries represent a natural control group for new EU member countries, we want to make sure that such choice does not drive the results. For this reason, we randomly draw 1,000 samples of inmates from outside the new EU member or candidate member countries and rerun the estimates as if each of these placebo samples is the true treated group (we maintain the same group size, 724 individuals). Figure 9 shows that the densities of the placebo effects are centered around zero, suggesting that the change in recidivism experienced by the control group after the EU enlargement is not abnormal; what clearly is abnormal is the estimated effect for the true treated group (vertical line), but only for economically motivated offenders. The $p$ value reported in the last column of Table 7 equals the probability that the effect estimated for a randomly drawn placebo sample is negative and larger, in absolute value, than the one estimated for the true treated group. Such probability is always very low for the subsample of economically motivated offenders ( 0.1 percent when estimated from the Cox model), while the $p$-value is 25 to 27 percent in the case of violent offenders.

Placebo dates of enlargement. - We also run a series of falsification tests at different placebo dates (rather than across placebo groups), in order to exclude the possibility that we are capturing the effect of some other event besides the EU enlargement. In the spirit of structural break tests with unknown breakpoint (Andrews, 1993), Figure 10 plots the ratio of the $R^{2}$ of the difference-in-differences model estimated at each placebo date in our sample period over the $R^{2}$ of a restricted specification without the interaction term, distinguishing between different subsamples. The most likely break point for Italy as a whole is December 12, which is very close to the official date of the enlargement and is consistent with anticipation effects as uncertainty unravels during the last few weeks of 2006 (see Section II.A). The break points estimated separately for northern and southern regions are very similar (December 1 and December 7), although the additional explanatory power is much greater in the former case (as is consistent with the evidence in Tables 3 35 ). 

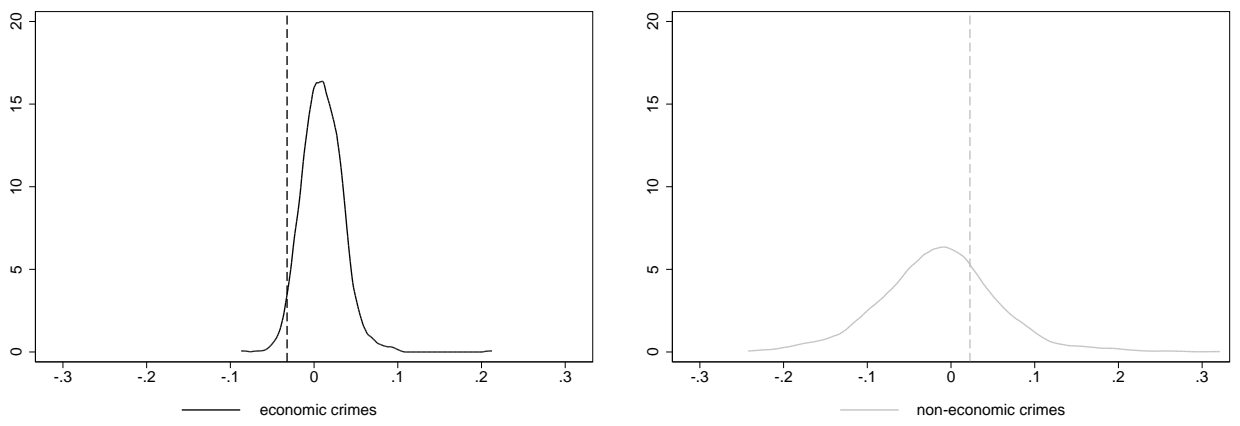

Figure 9. : The density of placebo effects

Note: The figure plots the distribution of placebo effects obtained for 1,000 samples that have the same size as the treated group (724 individuals) but are randomly drawn from the population of former inmates that belong neither to the treated nor to the control group. The effects estimated for the true treated groups are shown with a vertical line.

Attrition. - In principle, the Romanians and Bulgarians in our sample could have moved to other EU countries after obtaining legal status in the EU as a whole, in which case the reduction in the hazard rate of reincarceration would be due to the fact that they spent less time in the pool at risk (rather than due to changes in criminal behavior). Yet there are at least three reasons why differential attrition between the treated and control groups cannot explain the results (or may actually bias our estimates toward zero). First, the tourist visa waiver granted in 2001 to Romanians and Bulgarians, and the absence of border enforcement within the EU area (see Section II.A), allowed for significant mobility already before 2007. Indeed, the 90-day term limit imposed on the visa waiver was computed separately for each destination country in the EU, so between 2001 and 2007 Romanians and Bulgarians had the greatest incentive to travel frequently across different countries within the EU in order to avoid illegality. Therefore, the attrition rates for the treated group should have been higher before 2007, in which case our estimates of the differencein-difference effect would be biased toward zero. Second, our findings point to a greater effect for economically motivated offenders in regions that offer relatively better income opportunities to legal immigrants. There is no clear reason why outflows toward other EU countries should have been greater for such categories of immigrants; if anything, we should expect the opposite.

Interactions In CRIME. - Finally, we address the concern that the (change in) criminal behavior of Romanians and Bulgarians may have influenced the behavior of the control group, because of interactions in crime between different communities of immigrants. If immigrants in the control group increased their criminal activity in response to the decrease by Romanians and Bulgarians-i.e., if there are substitution effects, our estimates would be inflated-the opposite would occur in the case of complementarities. 


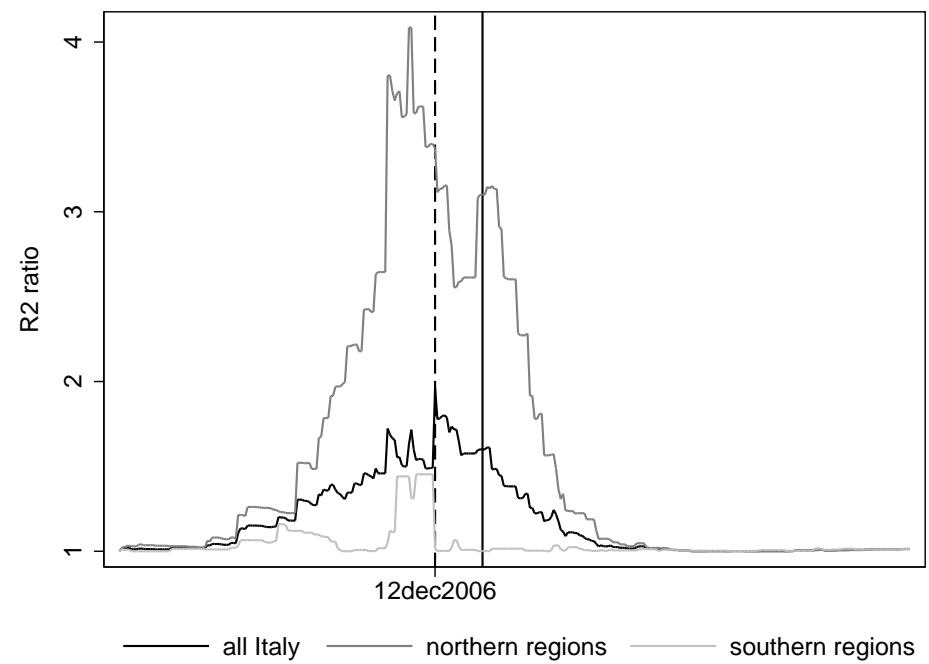

Figure 10. : Structural break test

Note: The graph plots the ratio of the $R^{2}$ of the difference-in-differences in reincarceration between treatment and control groups before and after each possible (placebo) treatment date in our sample period over the $R^{2}$ of a restricted specification without the difference-in-differences term. The vertical dashed line corresponds to the day that maximizes the $R^{2}$-ratio (i.e., the most likely break point), while the vertical solid line is the official date of the EU enlargement.

To address this issue we explicitly include interactions in crime into our empirical specification, allowing the hazard rate of each individual to depend upon that of his peers, both in his own and in the other group, and we follow Drago, Galbiati and Vertova (2009) and Drago and Galbiati (2012) in exploiting quasi-random variation in commuted sentence to identify such effects. In Section II.B we mentioned that, whenever released inmates are rearrested within 5 years, the commuted residual sentence gets added to the new one. Conditional upon the initial sentence, the commuted sentence varies only by the date in which the first crime was committed, which in turn generates quasi-random variation in the expected future sentence. Drago, Galbiati and Vertova $(2009)$ exploit this source of variation to identify the deterrence effect of the expected sentence on the probability of reincarceration, while Drago and Galbiati (2012) allow such probability to depend also upon the residual sentence of an inmate's peers, defined as inmates of the same nationality serving time in the same prison.

We further extend their specification to allow for interactions in crime between different communities. Specifically, for each individual in the treated group we form two distinct peer groups, including, respectively, all inmates in the treated and control groups that served time in the same prison. (We define analogously the peers of each individual in the control group.) A negative coefficient for the average residual sentence of the peers from the other community would suggest that peer effects go above and beyond the same 
nationality - i.e., that there are complementarities in crime across nationalities. A positive coefficient would indicate instead that inmates of a different nationality compete - i.e., there is substitution in criminal activity.

The results are presented in Table 8, Within our sample of new EU member and candidate member countries, we do find that (conditional upon the initial sentence) one's own residual sentence length lowers the hazard rate of rearrest, but the coefficients on the average residual sentence of peers of the same nationality is not significantly different from zero (column 1). Only if we use a larger sample, including all foreign inmates, do we find that peer effects within the same nationality matter (column 4). Most importantly for our purposes, the average residual sentence of the peers who belong to the other group does not seem to matter at all. The corresponding coefficient is never significantly different from zero, no matter whether we control (columns 3 and 6) or not (columns 2 and 5) for the average sentence of the peers of the same community. The coefficient is particularly small for our sample of new EU member and candidate member countries (columns 2-3).

The absence of direct interactions between inmates in the treated and control groups and their peers in the other group does not exclude the possibility of other (indirect) influences in equilibrium. For instance, the other communities could take on the criminal activities abandoned by Romanians and Bulgarians, in which case our estimates would be upwardly biased; alternatively, police forces could target these other communities more intensively after the decrease in crime by Romanians and Bulgarians, in which case our estimates would be downwardly biased. Figure 11 plots the change (between 2006 and 2007) in the number of crimes committed by all Romanians in Italy against the same changes for the nationalities included in the control group, for different types of crime ${ }^{24}$ A clearly positive correlation emerges between the two. While we can hardly attach any causal interpretation to this finding, this would hardly be consistent with strong substitution effects between the treated and control groups. If the positive correlation was driven by complementarities, our estimated effects of legal status would be biased toward zero.

\section{Conclusions}

We use a natural experiment, namely the last round of the EU enlargement, to identify the causal effect of legal status on immigrants' crime, which is a priori unclear: On the one hand, legal status may increase crime by precluding the expulsion of potential foreign criminals; on the other, it lowers the propensity to engage in crime by providing immigrants with alternative (legitimate) income opportunities. Evidence from a sample of former prison inmates released in Italy a few months before the enlargement suggests that the second effect prevails. In particular, the hazard rate of committing a crime decreases by about 50 percent after obtaining legal status as a consequence of the EU enlargement.

This is indeed a large effect. Still, it does not account for the entire difference in crime rates between legal and illegal immigrants, as computed in Section I.B. The remaining part (between $1 / 3$ and $1 / 2$ ) is likely driven by selection of immigrants into legal status

\footnotetext{
${ }^{24}$ These data are not available for Bulgarians and some other small foreign communities in the control group.
} 


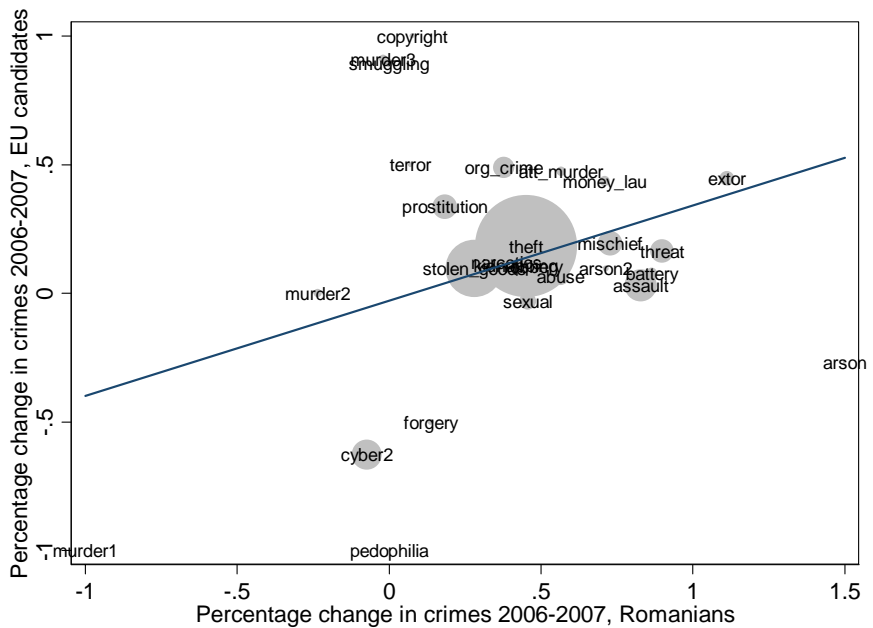

Figure 11. : Criminal offenses committed by immigrants from new EU member and candidate member countries, change over the 2006-2007 period

Note: The figure plots the (percentage) change between 2006 and 2007 in the number of Romanians arrested in Italy for different types of crimes against the same change for citizens of candidate member countries. The area of markers is proportional to the total number of offenses committed in each category.

and differences in the probability of incarceration conditional upon having committed a crime (which is constant across the pardoned inmates in our sample but may vary in general between legal and illegal immigrants). This strengthens the argument for a quasiexperimental approach, in order to correctly identify the effect of legal status.

What about the external validity of our results? Admittedly, former prison inmates represent a very peculiar group, so these findings cannot be easily generalized to the rest of the immigrant population. But the great majority of people never engage in any type of serious crime, which is why previous offenders represent an interesting sample to examine. This segment of the population is more likely to lie at the margin between a criminal career and legitimate activity, which is why recidivism studies form the bulk of the individual-level evidence in the empirical crime literature (see, for instance, Witte, 1980, Lee and McCrary, 2009).

From a policy perspective, our findings suggest that the consequences of migration policy depend crucially on enforcement. Whatever level of migration quotas is fixed, it should be enforced, in order to prevent the formation of a pocket of illegal immigrants with a very low opportunity cost of engaging in crime. Since 2010, the United States has been speeding deportations of convicted criminals while halting those of illegal immigrants without convictions. According to the U.S. Immigration and Customs Enforcement agency, in fiscal year 2011 just under 217,000 immigrants convicted of felonies or misdemeanors 
were deported, accounting for 55 percent of all deportations 25 On top of their effect of incapacitating deportees from committing future crimes in the country, such selective deportations are also likely to represent additional deterrence against crime committed by immigrants.

Finally, we focus only on the effects of the EU enlargement on the criminal activity of undocumented immigrants already in Italy before the enlargement. Changes in migration policy have far-reaching consequences for the size and composition of migration inflows. In particular, subsequent rounds of the EU enlargement or amnesties of formerly undocumented immigrants are likely to attract new immigrants from abroad, whose characteristics may differ considerably from those of previous migration waves. Policymakers would also need to estimate the costs and benefits along this additional dimension; this, however, goes beyond the scope of the present paper.

\section{REFERENCES}

Abadie, Alberto. 2005. "Semiparametric Difference-in-Differences Estimators." Review of Economic Studies, 72(1): 1-19.

Abadie, Alberto, and Guido W. Imbens. 2008. "On the Failure of the Bootstrap for Matching Estimators." Econometrica, 76(6): 1537-1557.

Accetturo, Antonio, and Luigi Infante. 2010. "Immigrant Earnings in the Italian Labour Market." Giornale degli Economisti, 69(1): 1-28.

Allison, P.D. 1982. "Discrete-Time Methods for the Analysis of Event Histories." Sociological Methodology, 13(1): 61-98.

Alonso-Borrego, César, Nuno Garoupa, and Pablo Vázquez. 2012. "Does Immigration Cause Crime? Evidence from Spain." American Law and Economics Review, 14(1): 165-191.

Amuedo-Dorantes, Catalina, Cynthia Bansak, and Steven Raphael. 2007. "Gender Differences in the Labor Market: Impact of IRCA." American Economic Review, 97(2): 412-416.

Andrews, Donald W. K. 1993. "Tests for Parameter Instability and Structural Change With Unknown Change Point." Econometrica, 61(4): 821-856.

Ashenfelter, Orley, and David Card. 2002. "Did the Elimination of Mandatory Retirement Affect Faculty Retirement?" American Economic Review, 92(4): pp. 957-980.

Baker, Scott. 2013. "Effects of Immigrant Legalization on Crime: The 1986 Immigration Reform and Control Act." Stanford University Unpublished Manuscript.

\footnotetext{
${ }^{25}$ See http://www.ice.gov/removal-statistics/
} 
Barbarino, Alessandro, and Giovanni Mastrobuoni. 2014. "The Incapacitation Effect of Incarceration: Evidence from Several Italian Collective Pardons." American Economic Journal: Economic Policy, 6(1): 1-37.

Barcellos, Silvia Helena. 2011. "Legalization and the economic status of immigrants." Santa Monica, CA: RAND WR-754.

Bauer, Thomas K., Magnus Lofstrom, and Klaus F. Zimmermann. 2000. "Immigration Policy, Assimilation of Immigrants and Natives' Sentiments towards Immigrants: Evidence from 12 OECD-Countries." IZA Discussion Paper No. $18 \%$.

Becker, Gary S. 1968. "Crime and Punishment: An Economic Approach." Journal of Political Economy, 76(2): pp. 169-217.

Bell, Brian, Stephen Machin, and Francesco Fasani. 2013. "Crime and Immigration: Evidence from Large Immigrant Waves." Review of Economics and Statistics, 95(4): 1278-1290.

Bianchi, Milo, Paolo Buonanno, and Paolo Pinotti. 2010. "Do Immigrants Cause Crime?" Journal of the European Economic Association, 10(6): 1318-1347.

Blangiardo, Giancarlo. 2008. "The centre sampling technique in surveys on foreign migrants. The balance of a multi-year experience." United Nations Statistical Commission and EUROSTAT Working Paper 12.

Borjas, George J. 1994. "The Economics of Immigration." Journal of Economic Literature, 32(4): 1667-1717.

Borjas, George J., Jeffrey Grogger, and Gordon H. Hanson. 2010. "Immigration and the Economic Status of African-American Men." Economica, 77(306): 255-282.

Bratsberg, Bernt, James F. Ragan, and Zafar M. Nasir. 2002. "The Effect of Naturalization on Wage Growth: A Panel Study of Young Male Immigrants." Journal of Labor Economics, 20(3): 568-597.

Busso, Matias, John DiNardo, and Justin McCrary. 2009. "New Evidence on the Finite Sample Properties of Propensity Score Matching and Reweighting Estimators." Institute for the Study of Labor (IZA) IZA Discussion Papers 3998.

Butcher, Kristin F., and Anne Morrison Piehl. 2007. "Why are Immigrants' Incarceration Rates so Low? Evidence on Selective Immigration, Deterrence, and Deportation." National Bureau of Economic Research, Inc NBER Working Papers 13229.

Butcher, Kristin F., and Anne M. Piehl. 1998. "Cross-City Evidence on the Relationship between Immigration and Crime." Journal of Policy Analysis and Management, 17(3): 457-493. 
Camarota, Steven A., and Jessica M. Vaughan. 2009. "Immigration and Crime: Assessing a Conflicted Issue." Center for Immigration Studies Backgrounder.

Card, David. 2005. "Is the New Immigration Really So Bad?" Economic Journal, 115(507): 300-323.

Card, David, and Phillip B. Levine. 2000. "Extended Benefits and the Duration of UI Spells: Evidence from the New Jersey Extended Benefit Program." Journal of Public Economics, 78(1-2): 107-138.

Card, David, Christian Dustmann, and Ian Preston. 2012. "Immigration, wages, and compositional amenities." Journal of the European Economic Association, 10(1): 78119.

Chojnicki, Xavier, Frédéric Docquier, and Lionel Ragot. 2005. "Should the U.S. Have Locked the Heaven's Door? Reassessing the Benefits of the Postwar Immigration." IZA Discussion Paper No. 1676.

Cortes, Patricia. 2008. "The Effect of Low-Skilled Immigration on U.S. Prices: Evidence from CPI Data." Journal of Political Economy, 116(3): 381-422.

Cox, D. R. 1972. "Regression Models and Life-Tables." Journal of the Royal Statistical Society. Series B (Methodological), 34(2): 187-220.

Dinas, Elias, and Joost van Spanje. 2011. "Crime Story: The Role of Crime and Immigration in the Anti-ImmigrationVote." Electoral Studies, 30(4): 658 - 671.

Drago, Francesco, and Roberto Galbiati. 2012. "Indirect Effects of a Policy Altering Criminal Behaviour: Evidence from the Italian Prison Experiment." American Economic Journal: Applied Economics, 4(2): 199-218.

Drago, Francesco, Roberto Galbiati, and Pietro Vertova. 2009. "The Deterrent Effects of Prison: Evidence from a Natural Experiment." Journal of Political Economy, 117(2): 257-280.

Eckaus, Richard S. 1961. "The North-South Differential In Italian Economic Development." The Journal of Economic History, 21(3): pp. 285-317.

Efron, Bradley. 1988. "Logistic Regression, Survival Analysis, and the Kaplan-Meier Curve." Journal of the American Statistical Association, 83(402): pp. 414-425.

Fasani, Francesco. 2008. "Undocumented Migration: Counting the Uncountable. Data and Trends across Europe." Clandestino Project (Country Report for Italy).

Fasani, Francesco. 2009. "Deporting Undocumented Immigrants." University College of London mimeo.

Freedman, Matthew, Emily Owens, and Sarah Bohn. 2013. "Immigration, Employment Opportunities, and Criminal Behavior." 
Friedberg, Rachel M., and Jennifer Hunt. 1995. "The Impact of Immigrants on Host Country Wages, Employment and Growth." Journal of Economic Perspectives, 9(2): 2344 .

Ghersi, Finocchi. 2005. "L'(In)attuazione della Legge Bossi-Fini: Prime Note per un Bilancio di Fine Legislatura [Commento a d.P.R. 18 Ottobre 2004, n. 334]." Giornale di Diritto Amministrativo, 11(6): 599-611.

Gould, Eric D., Bruce A. Weinberg, and David B. Mustard. 2002. "Crime Rates and Local Labor Market Opportunities in the United States: 1979-1997." Review of Economics and Statistics, 84(1): 45-61.

Grogger, Jeff. 1998. "Market Wages and Youth Crime." Journal of Labor Economics, 16(4): pp. 756-791.

Helliwell, John F., and Robert D. Putnam. 1995. "Economic Growth and Social Capital in Italy." Eastern Economic Journal, 21(3): 295-307.

Herm, Anne. 2008. "Recent migration trends: citizens of EU-27 Member States become ever more mobile while EU remains attractive to non-EU citizens." Eurostat-Statistics in Focus.

Italian Ministry of Internal Affairs. 2007. Rapporto sulla criminalità in Italia. Analisi, Prevenzione, Contrasto.

Kaushal, Neeraj. 2006. "Amnesty Programs and the Labor Market Outcomes of Undocumented Workers." Journal of Human Resources, 41(3): 631-647.

Kossoudji, Sherrie A., and Deborah A. Cobb-Clark. 2002. "Coming out of the Shadows: Learning about Legal Status and Wages from the Legalized Population." Journal of Labor Economics, 20(3): 598-628.

Lach, Saul. 2007. "Immigration and Prices." Journal of Political Economy, 115(4): 548587.

Lee, David S., and Justin McCrary. 2009. "The Deterrence Effect of Prison: Dynamic Theory and Evidence." Princeton University, Department of Economics, Industrial Relations Section. Working Papers 1171.

Lee, Ronald D., and Thimothy W. Miller. 2000. "Immigration, Social Security and Broader Fiscal Impacts." American Economic Review, 90: 350-354.

Lozano, Fernando, and Todd Sorensen. 2011. "The labor market value to legal status." Bonn, Germany: Institute for the Study of Labor IZA Working Paper.

Machin, Stephen, and Costas Meghir. 2004. "Crime and Economic Incentives." Journal of Human Resources, 39(4): 958-979. 
Marzio Barbagli and Asher Colombo. 2010. Rapporto sulla criminalità e la sicurezza in Italia. Ministero dell'Interno, Fondazione ICSA, Gruppo 24 Ore.

Mayda, Anna Maria. 2006. "Who is Against Immigration? A Cross-Country Investigation of Individual Attitudes Toward Immigrants." Review of Economics and Statistics, 88(3): 510-530.

Meyers, Samuel L, Jr. 1983. "Estimating the Economic Model of Crime: Employment versus Punishment Effects." The Quarterly Journal of Economics, 98(1): 157-66.

Moehling, Carolyn, and Anne Morrison Piehl. 2009. "Immigration, crime, and incarceration in early twentieth-century America." Demography, 46(4): 739-763.

Reid, Lesley Williams, Harald E Weiss, Robert M Adelman, and Charles Jaret. 2005. "The Immigration-Crime Relationship: Evidence across US Metropolitan Areas." Social Science Research, 34(4): 757-780.

Rubin, Donald B. 1974. "Estimating Causal Effects of Treatments in Randomized and Nonrandomized Studies." Journal of Educational Psychology, 66(5): 688 - 701.

Spenkuch, Jrg L. 2014. "Understanding the Impact of Immigration on Crime." American Law and Economics Review, 16(1): 177-219.

Stana, Richard M. 2005. "Information on Criminal Aliens Incarcerated in Federal and State Prisons and Local Jails." US Government Accountability Office (GAO) GAO, 05337R.

Storesletten, Kjetil. 2000. "Sustaining fiscal policy through immigration." Journal of Political Economy, 108(2): 300-323.

Van den Berg, Gerard J. 2001. "Duration Models: Specification, Identification and Multiple Durations." In Handbook of Econometrics. Vol. 5, , ed. J.J. Heckman and E.E. Leamer, Chapter 55, 3381-3460. Elsevier.

Wadsworth, Tim. 2010. "Is Immigration Responsible for the Crime Drop? An Assessment of the Influence of Immigration on Changes in Violent Crime Between 1990 and 2000." Social Science Quarterly, 91(2): 531-553.

Waters, Mary C., and Jessica T. Simes. 2013. "The Politics of Immigration and Crime." In The Oxford Handbook on Ethnicity, Crime and Immigration. , ed. Sandra M. Bucerius and Michael Tonry, 457-483. Oxford University Press.

Winegarden, C. R., and Lay Boon Khor. 1991. "Undocumented Immigration and Unemployment of U.S. Youth and Minority Workers: Econometric Evidence." Review of Economics and Statistics, 73(1): 105-112.

Witte, Ann Dryden. 1980. "Estimating the Economic Model of Crime with Individual Data." The Quarterly Journal of Economics, 94(1): 57-84. 
Table 3-: Probability of re-incarceration for pardoned inmates from new EU member and candidate member countries, before and after the EU enlargement

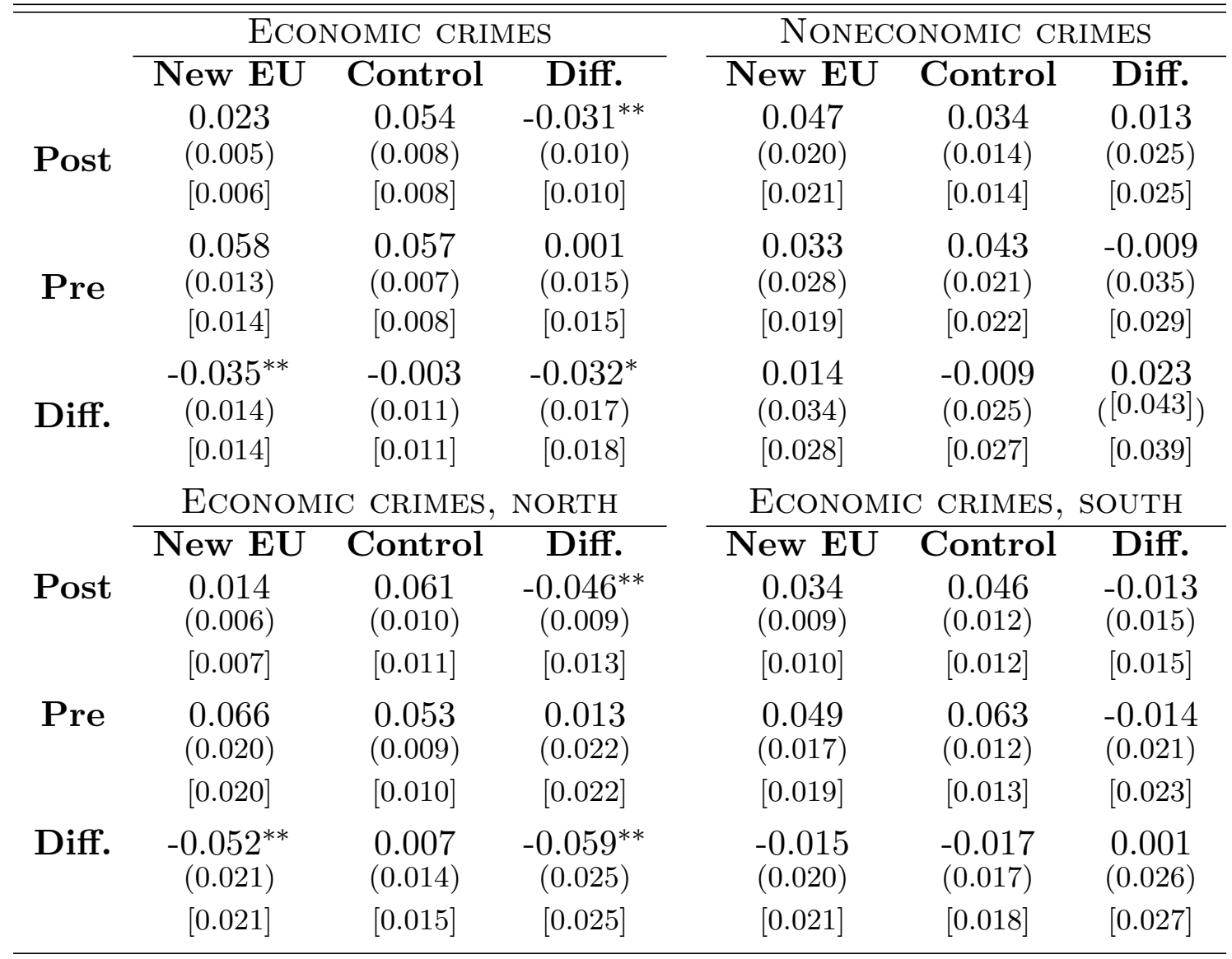

Note: This table reports the fraction of citizens of new EU member and candidate member countries that are reincarcerated before ("pre") and after ("post") the enlargement, as well as the difference and difference-in-differences between the two groups for different subsamples of pardoned inmates. The top left and right panels show the cross tabulation for the subsamples of individuals that were previously incarcerated (before the pardon) for economic and violent crimes, while the bottom left and right panels distinguish between economic offenders in northern and southern Italy. Observations are weighted by the inverse propensity score according to Eq. (4). Robust standard errors clustered by Italian region and country of origin are reported in parentheses. ${ }^{*},{ }^{* *}$, and ${ }^{* * *}$ denote betweengroup differences that are statistically significant at the 90 percent confidence, 95 percent confidence, and 99 percent confidence levels. Bootstrapped standard errors, based on 400 replications, are also reported in square brackets. 
Table 4-: Cox model for the hazard rate of re-incarceration

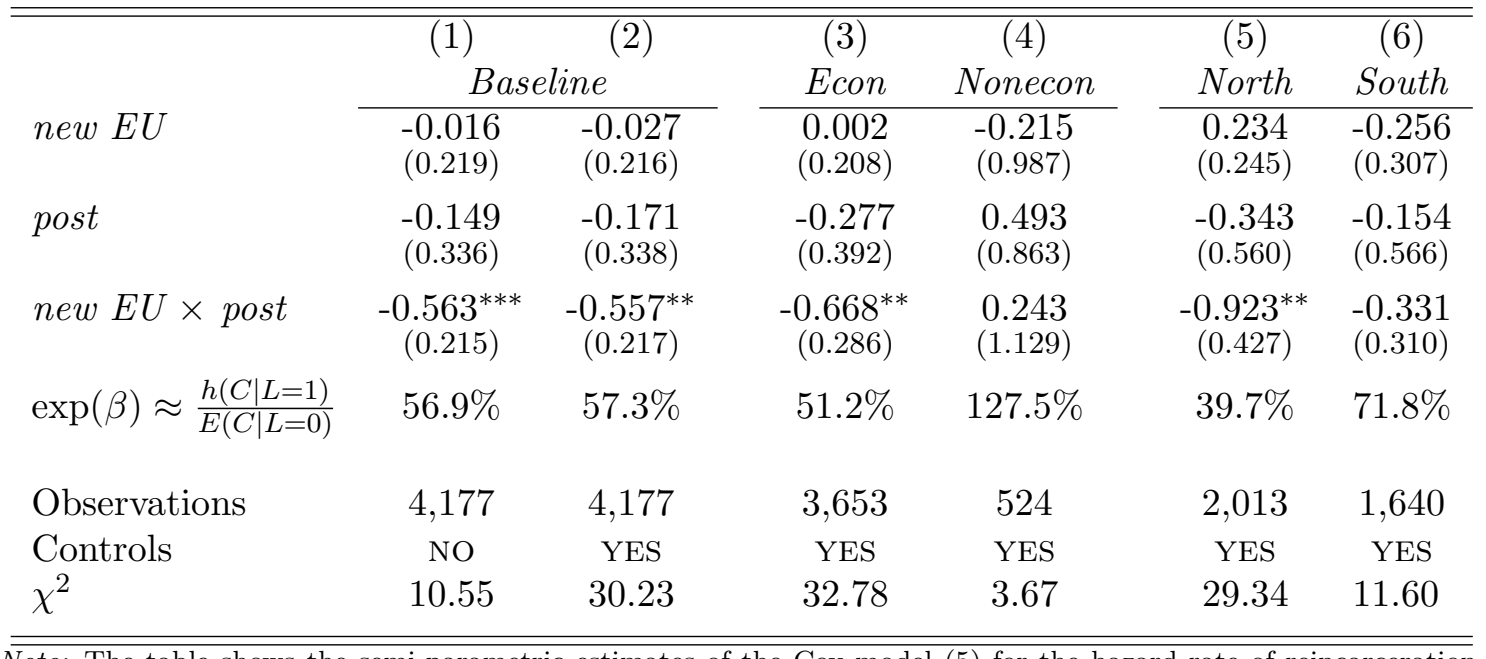

Note: The table shows the semi-parametric estimates of the Cox model 45 for the hazard rate of reincarceration. The main explanatory variables are a dummy for citizens of new EU member countries, new EU; a dummy for the period after the EU enlargement, post, and the interaction between the two. The exponentiated coefficient of the interaction term provides an estimate for the hazard ratio of legal status, see Equation (6). The specifications in columns (2) to (6) include as additional regressors age, age squared, a dummy for being married, and the length of the sentence commuted with the pardon. Regressions are weighted by the inverse propensity score according to Equation (4). Robust standard errors clustered by Italian region and country of origin are reported in parentheses. ${ }^{*},{ }^{* *}$, and ${ }^{* * *}$ denote coefficients significantly different from zero at the 90 percent confidence, 95 percent confidence, and 99 percent confidence levels. 
Table 5-: Logit model for the probability of re-incarceration

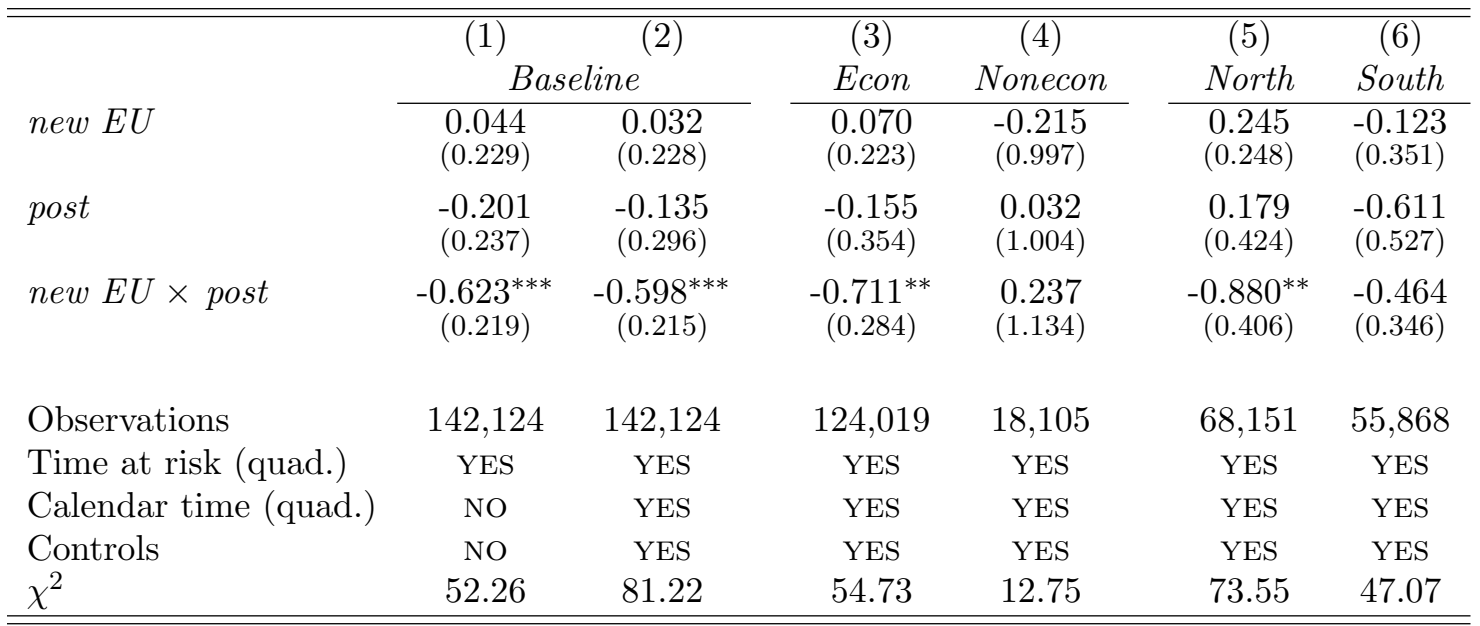

Note: The table shows the parametric estimates of a Logit model for the probability of incarceration for immigrants from new EU member and candidate member countries before and after the EU enlargement. The main explanatory variables are a dummy for citizens of new EU member countries, new EU, a dummy for the period after the EU enlargement, post; and the interaction between the two. The panel of observations is unbalanced because we include only the individuals who are at risk of rearrest in any given week. All specifications include a quadratic polynomial for the duration of time at risk; columns (2) to (6) include, in addition, a quadratic polynomial for calendar time and additional individual characteristics-namely age, age squared, a dummy for being married and the length of the sentence commuted with the pardon. Regressions are weighted by the inverse propensity score according to Equation (4). Robust standard errors clustered by Italian region and country of origin are reported in parentheses. ${ }^{*},{ }^{* *}$, and * denote coefficients significantly different from zero at the 90 percent confidence, 95 percent confidence, and 99 percent confidence levels. 
Table 6-: Exponential hazard model with and without unobserved heterogeneity

\begin{tabular}{|c|c|c|c|c|c|c|c|c|}
\hline \multirow[b]{2}{*}{ new EU } & (1) & \multicolumn{2}{|c|}{ Baseline } & (4) & $\begin{array}{c}(5) \\
\text { Econ }\end{array}$ & $\begin{array}{c}(6) \\
\text { Nonecon }\end{array}$ & $\begin{array}{c}(7) \\
\text { North }\end{array}$ & $\begin{array}{c}(8) \\
\text { South }\end{array}$ \\
\hline & $\begin{array}{l}-0.014 \\
(0.220)\end{array}$ & $\begin{array}{l}-0.021 \\
(0.254)\end{array}$ & $\begin{array}{c}-0.026 \\
(0.217)\end{array}$ & $\begin{array}{l}-0.057 \\
(0.253)\end{array}$ & $\begin{array}{l}-0.023 \\
(0.239)\end{array}$ & $\begin{array}{r}-0.301 \\
(0.871)\end{array}$ & $\begin{array}{c}0.248 \\
(0.288)\end{array}$ & $\begin{array}{l}-0.332 \\
(0.371)\end{array}$ \\
\hline post & $\begin{array}{c}-0.469^{* * *} \\
(0.136)\end{array}$ & $\begin{array}{l}-0.161 \\
(0.236)\end{array}$ & $\begin{array}{c}-0.468^{* * *} \\
(0.136)\end{array}$ & $\begin{array}{c}-0.090 \\
(0.312)\end{array}$ & $\begin{array}{l}-0.127 \\
(0.394)\end{array}$ & $\begin{array}{l}1.054 \\
(1.590)\end{array}$ & $\begin{array}{c}0.058 \\
(0.517)\end{array}$ & $\begin{array}{r}-0.039 \\
(1.127)\end{array}$ \\
\hline new $E U \times$ post & $\begin{array}{c}-0.559^{* * *} \\
(0.216)\end{array}$ & $\begin{array}{c}-0.779^{* * *} \\
(0.292)\end{array}$ & $\begin{array}{c}-0.554^{* *} \\
(0.218)\end{array}$ & $\begin{array}{c}-0.803^{* * *} \\
(0.331)\end{array}$ & $\begin{array}{c}-0.916^{* *} \\
(0.458)\end{array}$ & $\begin{array}{l}1.088 \\
(2.393)\end{array}$ & $\begin{array}{c}-1.321^{* *} \\
(0.671)\end{array}$ & $\begin{array}{l}-0.573 \\
(0.637)\end{array}$ \\
\hline $\exp (\beta) \approx \frac{h(C \mid L=1)}{E(C \mid L=0)}$ & 0.572 & 0.459 & 0.575 & 0.448 & 0.400 & 2.969 & 0.267 & 0.564 \\
\hline Heterogeneity & no & yes & no & yes & yes & yes & yes & yes \\
\hline Controls & no & no & yes & yes & yes & yes & yes & yes \\
\hline$\chi^{2}$ & 31.93 & 11.56 & 51.51 & 31.95 & 34.77 & 3.49 & 31.30 & 13.64 \\
\hline Observations & 4,177 & 4,177 & 4,177 & 4,177 & 3,653 & 524 & 2,013 & 1,640 \\
\hline
\end{tabular}

Note: The table shows the parametric estimates of an exponential hazard model for the probability of incarceration for immigrants from new EU member and candidate member countries before and after the EU enlargement. The main explanatory variables are a dummy for citizens of new EU member countries, new $E U$, a dummy for the period after the EU enlargement, post; and the interaction between the two. The specifications with additional controls include also a quadratic polynomial for calendar time and additional individual characteristics-namely age, age squared, a dummy for being married and the length of the sentence commuted with the pardon. The unobserved heterogeneity is assumed to be distributed according to the gamma distribution. Regressions are weighted by the inverse propensity score according to Eq. 44. Robust standard errors clustered by Italian region and country of origin are reported in parentheses. ${ }^{*},{ }^{* *}$, and ${ }^{* * *}$ denote coefficients significantly different from zero at the 90 percent confidence, 95 percent confidence, and 99 percent confidence levels.

Table 7-: Comparison between the actual treated group and the placebo samples

\begin{tabular}{|c|c|c|c|c|c|c|c|}
\hline & \multicolumn{5}{|c|}{ PLACEBO SAMPLES } & \multicolumn{2}{|c|}{ NEW EU } \\
\hline & mean & st. dev. & p5 & p50 & p95 & coeff. & p-value \\
\hline & \multicolumn{7}{|c|}{ difference-in-difference } \\
\hline Economic crimes & 0.010 & 0.024 & -0.027 & 0.009 & 0.048 & -0.032 & 0.026 \\
\hline Noneconomic crimes & -0.014 & 0.071 & -0.130 & -0.013 & 0.098 & 0.023 & 0.273 \\
\hline & \multicolumn{7}{|c|}{ Cox model, interaction coefficient } \\
\hline Economic crimes & 0.212 & 0.271 & -0.225 & 0.205 & 0.687 & -0.668 & 0.001 \\
\hline Noneconomic crimes & -0.166 & 2.883 & -1.920 & -0.405 & 1.458 & 0.243 & 0.249 \\
\hline
\end{tabular}

Note: The table shows the parametric estimates of an exponential hazard model for the probability of incarceration for immigrants from new EU member and candidate member countries before and after the EU enlargement. The main explanatory variables are a dummy for citizens of new EU member countries, new $E U$, a dummy for the period after the EU enlargement, post; and the interaction between the two. The specifications with additional controls include also a quadratic polynomial for calendar time and additional individual characteristics-namely age, age squared, a dummy for being married and the length of the sentence commuted with the pardon. The unobserved heterogeneity is assumed to be distributed according to the gamma distribution. Regressions are weighted by the inverse propensity score according to Eq. 4). Robust standard errors clustered by Italian region and country of origin are reported in parentheses. ${ }^{*},{ }^{* *}$, and ${ }^{* * *}$ denote coefficients significantly different from zero at the 90 percent confidence, 95 percent confidence, and 99 percent confidence levels. 
Table 8-: Interactions in criminal activity between treated and controls, estimates of peer effects

\begin{tabular}{|c|c|c|c|c|c|c|}
\hline \multirow[b]{3}{*}{ Residual sentence } & \multirow{2}{*}{\multicolumn{3}{|c|}{$\begin{array}{l}(1) \quad(2) \\
\text { Treatment and control group }\end{array}$}} & $(4)$ & $(5)$ & $(6)$ \\
\hline & & & & \multicolumn{3}{|c|}{ All foreign inmates } \\
\hline & $\begin{array}{l}-0.015^{*} \\
(0.008)\end{array}$ & $\begin{array}{l}-0.014^{*} \\
(0.008)\end{array}$ & $\begin{array}{l}-0.015^{*} \\
(0.009)\end{array}$ & $\begin{array}{c}-0.012^{* * *} \\
(0.003)\end{array}$ & $\begin{array}{c}-0.013^{* * *} \\
(0.003)\end{array}$ & $\begin{array}{c}-0.012^{* * *} \\
(0.003)\end{array}$ \\
\hline Peer residual sentence (same nationality) & $\begin{array}{l}0.010 \\
(0.007)\end{array}$ & & $\begin{array}{l}0.011 \\
(0.007)\end{array}$ & $\begin{array}{c}-0.009^{* *} \\
(0.005)\end{array}$ & & $\begin{array}{c}-0.011^{* *} \\
(0.005)\end{array}$ \\
\hline Peer residual sentence (other nationalities) & & $\begin{array}{r}-0.001 \\
(0.011)\end{array}$ & $\begin{array}{c}-0.004 \\
(0.011)\end{array}$ & & $\begin{array}{l}0.014 \\
(0.010)\end{array}$ & $\begin{array}{l}0.013 \\
(0.010)\end{array}$ \\
\hline Sentence & $\begin{array}{c}-0.007^{*} \\
(0.004)\end{array}$ & $\begin{array}{r}-0.006 \\
(0.004)\end{array}$ & $\begin{array}{c}-0.007^{*} \\
(0.004)\end{array}$ & $\begin{array}{c}-0.004^{* *} \\
(0.002)\end{array}$ & $\begin{array}{c}-0.005^{* * *} \\
(0.002)\end{array}$ & $\begin{array}{c}-0.004^{* *} \\
(0.002)\end{array}$ \\
\hline Controls & YES & YES & YES & YES & YES & YES \\
\hline Observations & 1767 & 1746 & 1746 & 6567 & 6565 & 6565 \\
\hline Pseudo $R$-sq. & 0.0111 & 0.0103 & 0.0115 & 0.00689 & 0.00640 & 0.00699 \\
\hline N. clusters & 331 & 320 & 320 & 1121 & 1120 & 1120 \\
\hline$\chi 2$ & 36.92 & 32.99 & 36.94 & 124.47 & 121.35 & 124.54 \\
\hline
\end{tabular}

Note: The table shows hazard ratios of a Cox proportional hazard model. The sample for the first three columns includes all inmates from new EU member and candidate member countries released after the July 2006 collective pardon. The remaining columns use a sample that contains all foreign inmates. Robust standard errors clustered by Italian region and country of origin are reported in parentheses. ${ }^{*},{ }^{* *}$, and ${ }^{* * *}$ denote coefficients significantly different from zero at the 90 percent confidence, 95 percent confidence and 99 percent confidence levels. 